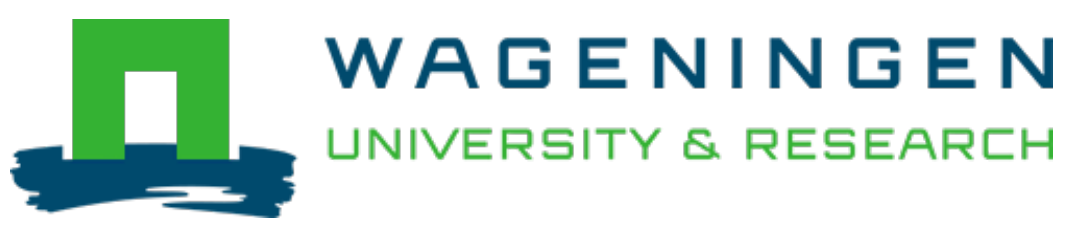

\title{
Past and current gene flow in the selfing, wind-dispersed species Mycelis muralis in western Europe
}

\author{
Molecular Ecology \\ Chauvet, S.; Velde, M.; Imbert, E.; Guillemin, M.L.; Mayol, M. et al \\ https://doi.org/10.1111/j.1365-294X.2004.02166.x
}

This article is made publicly available in the institutional repository of Wageningen University and Research, under the terms of article $25 \mathrm{fa}$ of the Dutch Copyright Act, also known as the Amendment Taverne. This has been done with explicit consent by the author.

Article 25 fa states that the author of a short scientific work funded either wholly or partially by Dutch public funds is entitled to make that work publicly available for no consideration following a reasonable period of time after the work was first published, provided that clear reference is made to the source of the first publication of the work.

This publication is distributed under The Association of Universities in the Netherlands (VSNU) 'Article $25 \mathrm{fa}$ implementation' project. In this project research outputs of researchers employed by Dutch Universities that comply with the legal requirements of Article $25 \mathrm{fa}$ of the Dutch Copyright Act are distributed online and free of cost or other barriers in institutional repositories. Research outputs are distributed six months after their first online publication in the original published version and with proper attribution to the source of the original publication.

You are permitted to download and use the publication for personal purposes. All rights remain with the author(s) and / or copyright owner(s) of this work. Any use of the publication or parts of it other than authorised under article $25 \mathrm{fa}$ of the Dutch Copyright act is prohibited. Wageningen University \& Research and the author(s) of this publication shall not be held responsible or liable for any damages resulting from your (re)use of this publication.

For questions regarding the public availability of this article please contact openscience.library@,wur.nl 


\title{
Past and current gene flow in the selfing, wind-dispersed species Mycelis muralis in western Europe
}

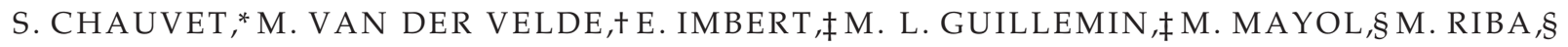 \\ M. J. M. SMULDERS, II B. VOSMAN, II L. ERICSON,${ }^{*}$ R. BIJLSMA + and B. E. GILES* \\ *Umeå University, Department of Ecology and Environmental Science, 90187 Umeå, Sweden, +University of Groningen, Department \\ of Genetics, Kerklaan 30, 9751 NN Haren, the Netherlands, łUniversité Montpellier 2, Institut des Sciences de l'Evolution, Laboratoire \\ Génétique et Environnement, Place Eugène Bataillon, 34095 Montpellier, France, §Centre de Recerca Ecològica i Aplicacions Forestals, \\ Universitat Autònoma de Barcelona, Bellaterra, 08193 Barcelona, Spain, IIPlant Research International, PO Box 16, 6700 AA \\ Wageningen, the Netherlands
}

\begin{abstract}
The distribution of genetic diversity in Mycelis muralis, or wall lettuce, was investigated at a European scale using 12 microsatellite markers to infer historical and contemporary forces from genetic patterns. Mycelis muralis has the potential for long-distance seed dispersal by wind, is mainly self-pollinated, and has patchily distributed populations, some of which may show metapopulation dynamics. A total of 359 individuals were sampled from 17 populations located in three regions, designated southern Europe (Spain and France), the Netherlands, and Sweden. At this within-region scale, contemporary evolutionary forces (selfing and metapopulation dynamics) are responsible for high differentiation between populations $\left(0.34<F_{\mathrm{ST}}<0.60\right)$ but, contrary to expectation, levels of within-population diversity, estimated by Nei's unbiased expected heterozygosity $\left(H_{\mathrm{E}}\right)\left(0.24<H_{\mathrm{E}}<0.68\right)$ or analyses of molecular variance $(50 \%$ of the variation found within-populations), were not low. We suggest that the latter results, which are unusual in selfing species, arise from efficient seed dispersal that counteracts population turnover and thus maintains genetic diversity within populations. At the European scale, northern regions showed lower allelic richness $(A=2.38)$ than populations from southern Europe $(A=3.34)$. In light of postglacial colonization hypotheses, these results suggest that rare alleles may have been lost during recolonization northwards. Our results further suggest that mutation has contributed to genetic differentiation between southern and northern Europe, and that Sweden may have been colonized by dispersers originating from at least two different refugia.
\end{abstract}

Keywords: admixture, metapopulation dynamics, microsatellites, Mycelis muralis, postglacial colonization, selfing

Received 29 October 2003; revision received 4 February 2004; accepted 4 February 2004

\section{Introduction}

During the Quaternary, the distribution of all species went through repeated episodes of contraction and expansion of their geographical ranges following changes in temperature associated with glaciations (Hewitt 1996). In Europe, these episodes were characterized by the extinction of northern populations when temperatures decreased, followed by northward expansion from southern refugia during inter-

Correspondence: Stéphanie Chauvet. Fax: + 469078667 05; E-mail: chauvet_st@hotmail.com glacial periods. Some evidence indicates that recolonization of northern areas did not proceed in slow and progressive waves, but rather in successive steps as long-distance dispersers reached unoccupied habitats where they expanded to form new populations, which then served as new propagule pools for further northward colonization (Petit et al. 1997; Clark et al. 1998; Cain et al. 2000; Hewitt 1999, 2000). Such rapid colonization processes may have strong effects on the distribution of genetic variation. Repeated bottlenecks may lead to increased genetic differentiation among recently colonized populations and to losses of genetic diversity as rarer alleles are lost along the colonization routes 
(Hewitt 1996, 2000; Taberlet et al. 1998). This decrease of genetic diversity following postglacial expansion has been observed throughout the world in different groups of plants with various life cycles, including tree species (Fagus sylvatica L., Comps et al. 2001; Pilgerodendron uviferum, Premoli et al. 2002), shorter-lived species (Calluna vulgaris, Mahy et al. 1999 and Rendell \& Ennos 2002) and perennial herbs (Silene regia, Dolan 1994; Asclepias exaltata, Broyles 1998).

In addition to historical events, the distribution of genetic variation is also affected by contemporary evolutionary forces related to life-history traits and population dynamics (Hamrick \& Godt 1996). These forces can either counteract and nullify historical patterns of genetic diversity (Ford et al. 1998; Comes \& Abbott 2000; van der Velde \& Bijlsma 2003), or act in similar directions, potentially allowing detection of the historical patterns. Among these contemporary forces, self-fertilization decreases both effective population size and effective pollen flow, which are expected to result in reduced genetic diversity within populations and enhanced genetic differentiation among populations (Jarne 1995; Ingvarsson 2002; Charlesworth 2003). Repeated founding events associated with metapopulation dynamics (i.e. subdivided, but to some extent interconnected demes with nonzero probabilities of demic extinction and recolonization) may also decrease genetic diversity within and increase genetic differentiation among local populations (Wade \& McCauley 1988; Giles \& Goudet 1997; Ingvarsson et al. 1997). These effects will be strongest where colonists are derived from single rather than multiple demes, and where rates of gene exchange among extant demes are low relative to the rates of population turnover (Whitlock \& McCauley 1990). The effects of postglacial colonization, selfing and metapopulation dynamics on the distribution of genetic variability are thus comparable in the sense that all of these processes are expected to reduce diversity within and enhance differentiation among populations. However, while the effects of postglacial colonization are only expected in regions that were more recently colonized, selfing and metapopulation dynamics act on more local spatial and temporal scales and are thus expected to affect genetic diversity in both Pleistocene refugia and recently colonized regions. Studies of genetic structure may thus reveal the relative influences of historical and contemporary evolutionary forces in shaping existing patterns of genetic diversity, and provide information on the potential for future evolution, including speciation and local adaptation (Avise 1994).

Mycelis muralis (Asteraceae), or wall lettuce, has a number of features making it a suitable system for investigating the influences of historical and contemporary forces on the distribution of genetic diversity. This herbaceous perennial is now found throughout most of temperate Europe, from eastern Spain to southern Scandinavia, and from the United Kingdom to the Black Sea, where it is limited by the $-7^{\circ} \mathrm{C}$ mean January isocline in the north and by the $25^{\circ} \mathrm{C}$ mean
July isocline in the south (Clabby \& Osborne 1999; Fig. 1). Although geographically widespread, $M$. muralis is typically uncommon and locally patchy. It is confined to basic, nutrientrich substrates and is a woodland species most commonly found in the openings, margins and clearings of temperate deciduous or mixed forests, and to a lesser extent along walls, pathways, streams, river banks, shingle beaches, or urban habitats (Ellenberg 1988; Clabby \& Osborne 1999). Since some of these habitats are successional, this species can undergo population turnover (i.e. metapopulation dynamics); extinction and colonization occur when habitat requirements are no longer fulfilled and when new habitat becomes available, respectively. Extinction, recolonization and new establishment of $M$. muralis populations have been observed in an ongoing species inventory started 30 years ago in south boreal Sweden (L. Ericson, unpublished data). Mycelis muralis is diploid $(2 n=18)$ and reproduces by seeds, primarily through self-pollination (Mejias 1994). Levels of genetic diversity are thus expected to be low within populations of this species. Selfing alone may reduce effective population sizes by up to two-fold, resulting in concomitant reductions in within-population genetic diversity (Pollak 1987). In a metapopulation context, reductions in diversity may be even greater because the low rates of pollen migration associated with high selfing rates are unable to compensate for the loss of genetic diversity resulting from repeated founding events (Ingvarsson 2002). In contrast to what has been demonstrated for some tree species (Liepelt et al. 2002), the low levels of pollen-mediated gene flow are also unlikely to have confounded the long-term genetic effects of refugial isolation or eradicated the patterns established during postglacial colonization. Mycelis muralis seeds also bear a pappus facilitating dispersal by wind, potentially over long distances. This species thus had the potential for a stepwise recolonization after the last glaciation, which may have resulted in a loss of genetic diversity as colonization proceeded northwards and in an increased genetic differentiation among populations in more recently colonized regions.

Using 12 nuclear microsatellite loci, we analysed the distribution of genetic variation of M. muralis in 17 populations distributed in three European regions: southern Europe (Spain and south of France), the Netherlands, and Sweden. Unfortunately, information about the late- or postglacial history of M. muralis does not exist (Clabby \& Osborne 1999). We assume that the present ecological and climatic conditions in which $M$. muralis is now found mirror the demands of the past and that during the last glaciation, $M$. muralis was present in southern Europe (the Iberian peninsula has been shown to be one of the three main European refugia for most plant species along with Italy and the Balkans). This species did not survive in Sweden, which was entirely ice-covered, or in the Netherlands, which were situated in the permafrost zone near to the ice edge (Taberlet et al. 1998; Hewitt 1999). Northward recolonization did not 


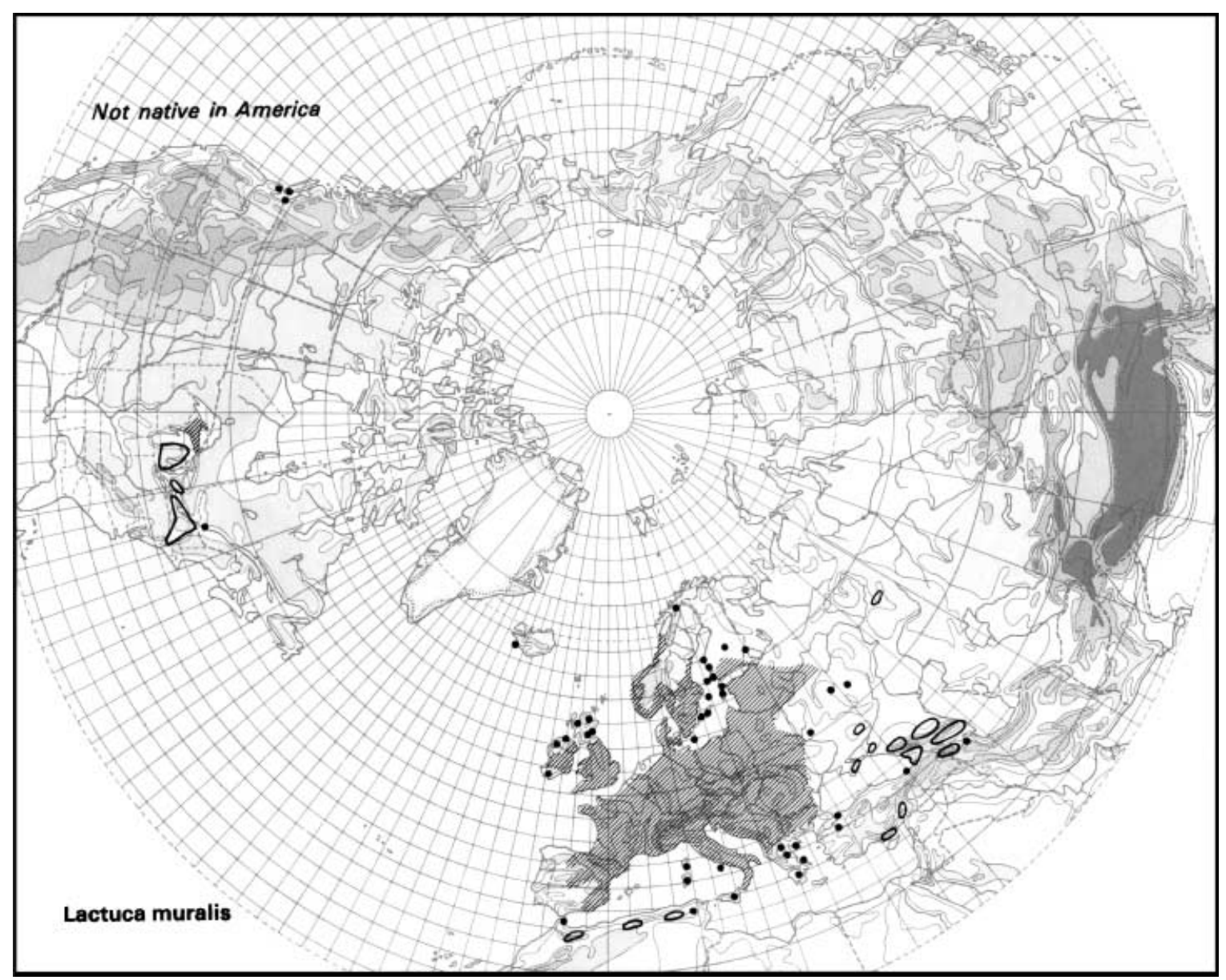

Fig. 1 Distribution map of Mycelis muralis (previously Lactuca muralis). Source: Hultén \& Fries (1986); reprinted with kind permission from Koeltz Scientific Books, Koenigstein, Germany. See http://linnaeus.nrm.se/flora/di/astera/mycel/mycemur.html.

begin earlier than 18000 years before the present, the time of the glacial maximum (Hewitt 1999). Macrofossil and palynological data for deciduous tree species with roughly the same habitat demands as $M$. muralis and components of the forest types with which M. muralis is now associated in Sweden, indicate that conditions suitable for the survival of colonizing M. mycelis existed in central Sweden 7000-8000 years ago (Wallin 1996; Kullman 1998).

The goal of this study was to examine the relative importance of current evolutionary forces and past events in shaping the genetic variability of $M$. muralis. If the effects of current forces such as selfing and metapopulation dynamics are primarily responsible for the observed structure, and if their effects are similar in each region, then we expect low within-population diversity and high among-population differentiation in all regions. Over and above the effects of these local forces, we expect lower genetic diversity within and higher differentiation among populations in the recently colonized regions (Sweden and the Netherlands) than in southern Europe if the effects of postglacial colonization processes continue to influence the distribution of genetic variation. If colonizers of Sweden and the Netherlands originated solely from southern European refugia, then alleles present in the two northern regions should be subsets of alleles present in southern Europe, with the exception of new alleles created by mutations. Moreover, colonization from southern to northern Europe implies that the time elapsed since regions diverged is longer than the time of divergence among populations within regions. We thus expect that divergence time has been sufficient for mutation to contribute to population divergence at the larger European scale but not within regions.

\section{Materials and methods}

\section{Collection of samples}

Mycelis muralis populations were collected from 17 localities in Europe in 2000 and 2001. These localities were chosen from three different regions to assess the distribution of genetic variation along a north-south axis within Europe. Six populations were sampled from southern Europe 


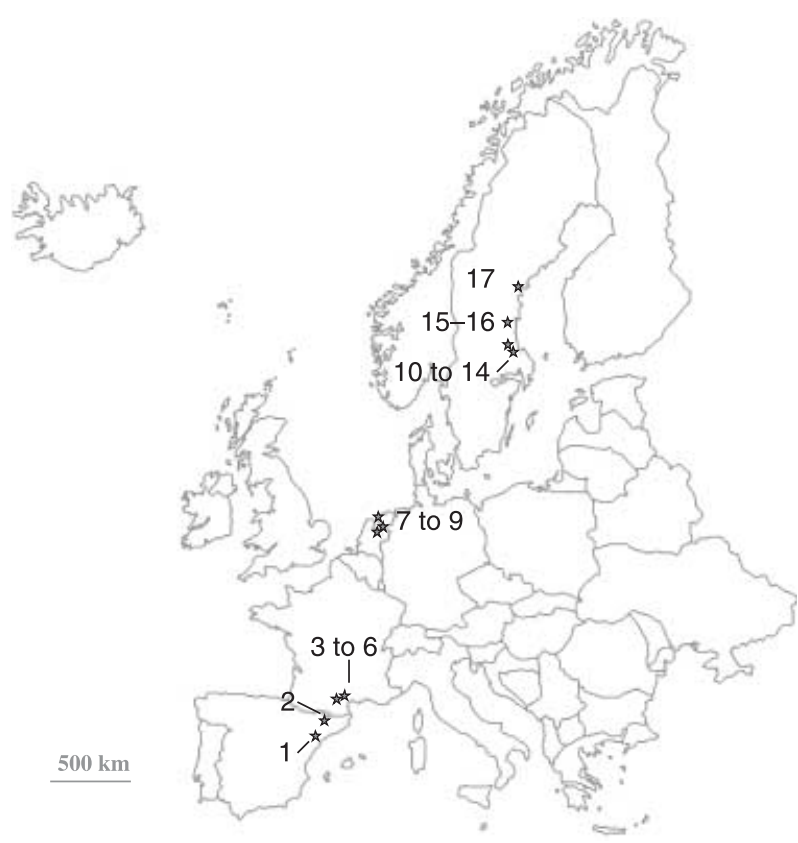

Fig. 2 Map showing locations of populations used in this study. Sites are: 1 = Castellfollit, $2=$ Balma, $3=$ Salesse, $4=$ Graissessac, $5=$ Radier, $6=$ Natges, $7=$ Ommen, $8=$ Emmen, $9=$ Groningen, 10 = Lötängen, 11 = Skutskär, 12 = Lövgrund, 13 = South Utvalnäs $14=$ Nöttersvearna, 15 = Lindefallet, 16 = ÖstanåBerget, $17=$ High Coast.

(SE: south of France and northern Spain), three from the northern part of the Netherlands (NL), and eight from Sweden (SW) (Fig. 2). Populations from Spain and Sweden lie near to the southern and northern limits of the current species distribution in Europe (Fig. 1). Distances between populations within regions varied between 8 and $480 \mathrm{~km}$, 75 and $130 \mathrm{~km}$, and 9 and $560 \mathrm{~km}$ for southern Europe, the Netherlands and Sweden, respectively. Populations in different regions were separated by $1480-4450 \mathrm{~km}$ and their locations are described in Table 1. For some of the populations (1-9, 11 and 12), samples were collected as seeds from 10 to 30 mother plants growing in the field during summer 2000. These seeds were germinated in a greenhouse, and genetic analysis was conducted on fresh leaves from one seedling per mother plant. Samples from the remaining populations (10 and 13-17) consisted of leaves collected from individual plants growing in the field during summer 2001 that were kept dried prior to genetic analysis. For all populations, the individuals from which seeds or leaves were sampled were chosen at random from the entire population area to ensure representative estimates of the within-population diversity.

\section{Microsatellite typing}

Genetic variation was analysed in 359 individuals from the 17 populations, with 10-30 individuals per site depending on population size (sample sizes given in Table 1). DNA was extracted from fresh or dried leaves using DNeasy Plant Mini Kit (QIAGEN). For all populations from southern Europe, the Netherlands and two from Sweden, individual genotypes were assessed using 12 polymorphic microsatellite loci isolated from the nuclear genome of M. muralis (WMM4, WMM5, WMM6, WMM7, WMM9, WMM12, WMM16, WMM18, WMM20, WMM21, WMM22 and WMM24) (van der Velde et al., paper under revision). All sequences used in this paper have been deposited in the EMBL database (accession numbers AJ617631-AJ617671). Individuals from the other Swedish populations were analysed for nine of the loci (WMM7, WMM18 and WMM21 showed few or no polymorphisms in Sweden and were hence not used). Amplification of DNA was performed using a polymerase chain reaction (PCR) method following van der Velde et al. (paper under revision). PCR products were analysed on an ABI 377 , and allele sizes were determined using GENESCAN 3.1 software.

\section{Data analysis}

Within-population genetic diversity. Allele frequencies, the proportion of polymorphic loci $\left(N_{p}\right)$, the mean number of alleles $(A)$ calculated using the rarefaction method (Leberg 2002), the observed $\left(H_{\mathrm{O}}\right)$ and Nei's unbiased expected $\left(H_{\mathrm{E}}\right)$ heterozygosities and $F_{\text {IS }}$ estimated according to Weir \& Cockerham (1984) were computed using FSTAT 2.9.3.2 software (Goudet 2001). The selfing rate per population was estimated using the relationship $s=2 F_{\text {IS }} /\left(1+F_{\text {IS }}\right)$ (Pollak 1987). Departures from Hardy-Weinberg equilibrium at each locus and genotypic linkage disequilibria between pairs of loci were tested within each population using GENEPOP 3.3 software (Raymond \& Rousset 1995).

To assess whether population diversity differs between regions, average values (over samples and loci) of $A, H_{\mathrm{O}^{\prime}}$ $H_{\mathrm{E}}$ and $F_{\mathrm{IS}}$ were calculated over populations within each region. Differences among regions were tested using a permutation test implemented in $F_{\mathrm{STAT}}$, which allocated whole samples (i.e. populations) at random to the different groups (i.e. regions). Finally, to estimate whether populations from nonglaciated areas had higher genetic diversity than populations located in areas affected by glaciation, a second comparison of all genetic parameters was performed between southern (SE) and northern (NL + SW) European regions. Whether the selfing rate differed between southern and northern Europe was also investigated using a Mann-Whitney test. Note that all comparisons between regions were performed over the nine loci that were assessed in all populations.

Genetic structure among populations. Genetic differentiation was first assessed using FSTAT software to compute an exact 


\begin{tabular}{|c|c|c|c|}
\hline Population & $N$ & Position & Habitat \\
\hline \multicolumn{4}{|l|}{ Southern Europe (SE) } \\
\hline 1-Castellfollit (Spain) & 19 & $41^{\circ} 19^{\prime} \mathrm{N} 01^{\circ} 02^{\prime} \mathrm{E}$ & Forest-treefall gap \\
\hline 2-Balma (Spain) & 24 & $42^{\circ} 15^{\prime} \mathrm{N} 01^{\circ} 44^{\prime} \mathrm{E}$ & Open forest \\
\hline 3-Salesse (France) & 16 & $43^{\circ} 40^{\prime} \mathrm{N} 02^{\circ} 51^{\prime} \mathrm{E}$ & Path border \\
\hline 4-Graissessac (France) & 10 & $43^{\circ} 41^{\prime} \mathrm{N} 03^{\circ} 05^{\prime} \mathrm{E}$ & Factory ruins \\
\hline 5-Radier (France) & 30 & $43^{\circ} 53^{\prime} \mathrm{N} 03^{\circ} 30^{\prime} \mathrm{E}$ & Stream border \\
\hline 6-Natges (France) & 27 & $43^{\circ} 50^{\prime} \mathrm{N} 03^{\circ} 35^{\prime} \mathrm{E}$ & Forest path border \\
\hline \multicolumn{4}{|l|}{ The Netherlands (NL) } \\
\hline 7-Ommen & 20 & $52^{\circ} 31^{\prime} \mathrm{N} 06^{\circ} 25^{\prime} \mathrm{E}$ & Roadside-forest edge \\
\hline 8-Emmen & 10 & $52^{\circ} 48^{\prime} \mathrm{N} 06^{\circ} 55^{\prime} \mathrm{E}$ & Roadside-forest edge \\
\hline 9-Groningen & 20 & $53^{\circ} 13^{\prime} \mathrm{N} 06^{\circ} 35^{\prime} \mathrm{E}$ & Urban habitat \\
\hline \multicolumn{4}{|l|}{ Sweden (SW) } \\
\hline 10-Lötängen & 30 & $60^{\circ} 35^{\prime} \mathrm{N} 17^{\circ} 24^{\prime} \mathrm{E}$ & Open forest \\
\hline 11-Skutskär & 21 & $60^{\circ} 37^{\prime} \mathrm{N} 17^{\circ} 25^{\prime} \mathrm{E}$ & Graveyard \\
\hline 12-Lövgrund & 20 & $60^{\circ} 45^{\prime} \mathrm{N} 17^{\circ} 26^{\prime} \mathrm{E}$ & Stony beach \\
\hline 13-South Utvalnäs & 21 & $60^{\circ} 44^{\prime} \mathrm{N} 17^{\circ} 19^{\prime} \mathrm{E}$ & Meadow \\
\hline 14-Nöttersvearna & 25 & $60^{\circ} 53^{\prime} \mathrm{N} 17^{\circ} 02^{\prime} \mathrm{E}$ & Forest \\
\hline 15-Lindefallet & 18 & $61^{\circ} 28^{\prime} \mathrm{N} 16^{\circ} 52^{\prime} \mathrm{E}$ & Forest \\
\hline 16-ÖstanåBerget & 25 & $61^{\circ} 38^{\prime} \mathrm{N} 17^{\circ} 02^{\prime} \mathrm{E}$ & Forest Path border \\
\hline 17-High Coast & 23 & $62^{\circ} 54^{\prime} \mathrm{N} 18^{\circ} 24^{\prime} \mathrm{E}$ & Forest \\
\hline
\end{tabular}

Table 1 Sample sizes $(N)$, locations and habitat of the Mycelis muralis populations analysed for microsatellite markers

The 17 populations were grouped into three regions: southern Europe (populations 1-6), the Netherlands (populations 7-9) and Sweden (populations 10-17). Note that population 17 is at the northern border of the distribution range.

test of differentiation over all populations not assuming Hardy-Weinberg equilibrium, and to compute global and per locus $F_{\mathrm{ST}}$ (Weir \& Cockerham 1984). To examine whether, as expected, population differentiation was higher in recently colonized regions than in southern Europe following postglacial recolonization, global $F_{\mathrm{ST}}$ estimates were also calculated over populations within regions, and tests for differences between regions were performed using permutation procedures (permutation of genotypes among populations).

To assess whether mutation contributed to differentiation between populations, the SPAGEDI 1.1 software (Hardy \& Vekemans 2002) was used to compute and compare two global and pairwise statistics: $F_{\mathrm{ST}}$ based on allele identity/ nonidentity and $R_{\mathrm{ST}}$ that also takes allele size information into account. When the mutation rate is negligible in comparison to migration and drift (i.e. $\mu<<m$ ), $R_{\mathrm{ST}}$ and $F_{\mathrm{ST}}$ should give equivalent estimates of differentiation. Conversely, when stepwise-like mutations contribute to population differentiation (i.e. $\mu \geq m$ ), then $R_{\mathrm{ST}}$ is larger than $F_{\mathrm{ST}}$ (Hardy et al. 2003). A test procedure to compare $R_{\mathrm{ST}}$ and $F_{\mathrm{ST}}$ is implemented in SPAGEDI (see Hardy et al. 2003 for details). This procedure estimates the distribution of a statistic $\left(p R_{\mathrm{ST}}\right)$ under the null hypothesis that differences in allele sizes do not contribute to population differentiation. This distribution is obtained using a randomization procedure whereby the different allele sizes observed at a locus are randomly permuted, while the allele identity information is kept intact. Because allele identity but not size is taken into account when estimating $p R_{\mathrm{ST}}$, mean $p R_{\mathrm{ST}}$ should be equal to the expected $F_{\mathrm{ST}}$ value (Hardy et al. 2003). The test then compares the observed $R_{\mathrm{ST}}$ value to the distribution of $p R_{\mathrm{ST}}$. If $R_{\mathrm{ST}}$ is significantly larger than $p R_{\mathrm{ST}^{\prime}}$ then mutation contributes to genetic differentiation and follows, at least partially, a stepwise mutation process. If $R_{\mathrm{ST}}$ is not significantly different from $p R_{\mathrm{ST}}$, then allele size is not informative for population differentiation, either because the mutation process is not stepwise-like or because mutations have not contributed to differentiation (Hardy et al. 2003). In the case of M. muralis, a long-term divergence among regions and greater gene flow within regions are expected, implying that stepwise-like mutations should contribute more to population differentiation at the European but less (or not) at the regional scale. In a first analysis, global and pairwise $R_{\mathrm{ST}}$ and $F_{\mathrm{ST}}$ values were computed, distinguishing between pairs of populations within and among regions, and testing $R_{\mathrm{ST}}$ values by allelesize permutation (1000 permutations). Second, to investigate whether longer divergence time between the most distant regions (SE and SW) allowed a larger contribution of stepwise-like mutation to differentiation, $R_{\mathrm{ST}}$ and $p R_{\mathrm{ST}}$ were compared for all pairs of regions (SE/NL, SE/SW and NL/ SW). Note that these analyses can be performed for highly selfing species (Hardy et al. 2003).

To examine the relative partitioning of genetic variation within and among regions, first, a hierarchical analysis of 
population structure was conducted using TFPGA 1.3 software (Miller 1997). $F_{\mathrm{IS}}, F_{\mathrm{IT}}, F_{\mathrm{SR}}$ and $F_{\mathrm{RT}}$ were estimated following Weir \& Cockerham (1984). $F_{\mathrm{SR}}$ is the differentiation of populations within regions and $F_{\mathrm{RT}}$ the differentiation among regions. Variances for these estimators were obtained by jack-knifing over loci. Second, using ARLEQUIN 2.000 software (Schneider et al. 2000), analyses of molecular variance (AMOVA) were conducted to partition the total variance into covariance components. First, all regions were included in the analysis to quantity the proportions of genetic variation due to differences among regions, among populations within regions, or within populations. To assess whether populations in recently colonized regions (NL and SW) were more strongly differentiated than those of southern Europe, AMOvA analyses were performed for each region separately to determine the partitioning of genetic variance within and among populations.

Genetic differentiation among populations was visualized by performing correspondence analyses on allele frequencies per population, using the AFC3D procedure implemented in GENETIX 4.03 software (Belkhir et al. 2002). Factorial axes are ordered according to their eigenvalues, the larger eigenvalue explaining more of the general structure contained in the dataset.

\section{Results}

\section{Variability within populations}

All 12 loci were polymorphic, with allele numbers ranging from three at locus WMM18 to 25 at locus WMM6. The number of alleles averaged over populations ranged between 1.11 at locus WMM18 and 4.17 at locus WMM6 (see Appendix I).

Variation within populations was high. Excluding population 8 , which was polymorphic at only one locus, at least two-thirds of the loci were polymorphic per population (Table 2). Among the 143 alleles recorded at the 12 loci, 72 were diagnostic for one of the three regions under study: 51 were private alleles recorded only in southern Europe, 19 were private alleles from Sweden, and 2 were private alleles from the Netherlands (Appendix I). Because the Netherlands were represented by only three populations, which furthermore had small effective population sizes as a result of small founder numbers (van der Velde $e t$ al. under review), the number of private alleles observed in the Netherlands is unfortunately not comparable to what is found in the two other regions. Among the 48 alleles observed in the Netherlands, 41 were also observed in southern Europe

\begin{tabular}{|c|c|c|c|c|c|c|}
\hline Population & $N_{p} / N_{a n a}$ & $A^{*}$ & $H_{\mathrm{O}}$ & $H_{\mathrm{E}}$ & $F_{\text {IS }}$ & $s$ \\
\hline \multicolumn{7}{|c|}{ Southern Europe } \\
\hline 1 & $11 / 12$ & $1.99(0.17)$ & $0.05(0.01)$ & $0.41(0.06)$ & 0.87 & 0.93 \\
\hline 2 & $12 / 12$ & $4.99(0.61)$ & $0.20(0.03)$ & $0.68(0.04)$ & 0.71 & 0.83 \\
\hline 3 & $11 / 12$ & $2.71(0.28)$ & $0.03(0.01)$ & $0.53(0.05)$ & 0.94 & 0.97 \\
\hline 4 & $12 / 12$ & $2.89(0.26)$ & $0.18(0.06)$ & $0.58(0.05)$ & 0.69 & 0.82 \\
\hline 5 & $12 / 12$ & $4.39(0.49)$ & $0.14(0.03)$ & $0.64(0.04)$ & 0.78 & 0.88 \\
\hline 6 & $12 / 12$ & $3.08(0.30)$ & $0.08(0.02)$ & $0.47(0.04)$ & 0.84 & 0.91 \\
\hline \multicolumn{7}{|c|}{ The Netherlands } \\
\hline 7 & $11 / 12$ & $2.24(0.21)$ & $0.06(0.02)$ & $0.42(0.05)$ & 0.86 & 0.92 \\
\hline 8 & $1 / 12$ & $1.11(0.11)$ & $0.02(0.02)$ & $0.04(0.04)$ & 0.56 & 0.72 \\
\hline 9 & $11 / 12$ & $2.53(0.13)$ & $0.01(0.01)$ & $0.37(0.03)$ & 0.98 & 0.99 \\
\hline \multicolumn{7}{|l|}{ Sweden } \\
\hline 10 & $9 / 9$ & $4.21(0.61)$ & $0.02(0.02)$ & $0.67(0.04)$ & 0.97 & 0.98 \\
\hline 11 & $8 / 12$ & $2.11(0.21)$ & $0.02(0.01)$ & $0.24(0.05)$ & 0.94 & 0.97 \\
\hline 12 & $10 / 12$ & $2.16(0.30)$ & $0.004(0.004)$ & $0.35(0.07)$ & 0.99 & 0.99 \\
\hline 13 & $9 / 9$ & $2.51(0.22)$ & $0.01(0.01)$ & $0.34(0.05)$ & 0.97 & 0.98 \\
\hline 14 & $9 / 9$ & $2.48(0.24)$ & $0.05(0.01)$ & $0.49(0.06)$ & 0.89 & 0.94 \\
\hline 15 & $8 / 9$ & $2.91(0.38)$ & $0.06(0.01)$ & $0.49(0.09)$ & 0.87 & 0.93 \\
\hline 16 & $8 / 9$ & $1.89(0.11)$ & $0.00(0.00)$ & $0.43(0.05)$ & 1.00 & 1 \\
\hline 17 & $7 / 9$ & $2.07(0.28)$ & $0.02(0.01)$ & $0.28(0.07)$ & 0.93 & 0.96 \\
\hline
\end{tabular}

$N_{p} / N_{a n a^{\prime}}$ the number of polymorphic loci out of the number of loci analysed; $A$, the mean number of alleles calculated with the rarefaction method; $H_{\mathrm{O}}$, the observed heterozygosity; $H_{\mathrm{E}^{\prime}}$ the Nei's unbiased gene diversity; $F_{\mathrm{IS}}$ the fixation index; and $s$, the selfing rate. Standard errors for $A, H_{\mathrm{O}}$ and $H_{\mathrm{E}}$ are given in parentheses. All parameters but $s$ are estimated using FSTAT software.

*Allelic richness based on minimum sample size of 10 diploid individuals and calculated over the nine loci analysed for all populations.

Table 2 Polymorphism at 12 microsatellite loci in the 17 populations described in Table 1 
(i.e. $85 \%$ ), whereas among the 74 alleles observed in Sweden, only 50 were also observed in southern Europe (i.e. 68\%).

The number of alleles per locus per population ranged between 1 and 11, with mean numbers of alleles calculated over loci ranging from 1.11 in population 8 to 4.99 in population 2 (Table 2). With the exception of population 8 , Nei's gene diversities $\left(H_{\mathrm{E}}\right)$ were high in all populations. The observed heterozygosities $\left(H_{\mathrm{O}}\right)$ were low (even zero in population 16), and within-population $F_{\text {IS }}$ and the estimated selfing rates were high in all populations (Table 2). These results confirm that selfing is the predominant form of mating in these populations. As a consequence, significant deviations from both linkage and Hardy-Weinberg equilibria are expected. Even though monomorphism for some loci in some populations precluded testing all possible combinations, 437 of 742 possible locus-pair tests indicated significant deviations from linkage equilibrium $(P<0.05)$ and 155 out of 161 population-locus combinations deviated from Hardy-Weinberg expectations $(P<0.05)$. After sequential Bonferroni corrections, 179 out of 742 locus-pairs were in linkage disequilibrium, and 142 out of 161 population-locus combinations deviated from HardyWeinberg expectations.

Comparison of the three regions revealed significant differences in the observed proportions of heterozygotes, with populations from southern Europe containing more heterozygotes than the other regions (Table 3). In contrast, there were no significant differences between regions for the mean number of alleles, gene diversities, or $F_{\text {IS }}$ estimates. When populations from the Netherlands and Sweden were pooled into one region (northern Europe $=\mathrm{NL}+\mathrm{SW}$ ), northern Europe had significantly lower proportions of heterozygotes and significantly higher values of $F_{\mathrm{IS}}$ than southern Europe (Table 4). Estimated selfing rates (Table 2)

Table 3 Comparison of population polymorphism among the regions southern Europe $(N=6)$, the Netherlands $(N=3)$ and Sweden $(N=8)$

\begin{tabular}{lllll}
\hline & $\begin{array}{l}\text { Southern } \\
\text { Europe }\end{array}$ & $\begin{array}{l}\text { The } \\
\text { Netherlands }\end{array}$ & Sweden & $P$ \\
\hline$A^{*}$ & 3.34 & 1.96 & 2.54 & 0.081 \\
$H_{\mathrm{O}}$ & 0.11 & 0.04 & 0.02 & $\mathbf{0 . 0 4 8}$ \\
$H_{\mathrm{E}}$ & 0.55 & 0.34 & 0.43 & 0.083 \\
$F_{\mathrm{IS}}$ & 0.80 & 0.89 & 0.94 & 0.091 \\
$F_{\mathrm{ST}}$ & 0.34 & 0.60 & 0.44 & 0.092 \\
\hline
\end{tabular}

$A$, the mean number of alleles calculated after rarefaction method; $H_{\mathrm{O}}$, the observed heterozygosity; $H_{\mathrm{E}}$, the gene diversity; $F_{\mathrm{IS}}$ and $F_{\mathrm{ST}}$ values are estimated according to Weir \& Cockerham (1984). Probability values for differences between regions are given for two-sided tests, after 10000 permutations. Analyses performed with $F_{\text {STAT }}$ software.

*Allelic richness based on minimum sample size of 10 diploid individuals.
Table 4 Comparison of population polymorphism between southern Europe $(N=6)$, and northern Europe $(\mathrm{NL}+\mathrm{SW}, N=11)$

\begin{tabular}{llll}
\hline & $\begin{array}{l}\text { Southern } \\
\text { Europe } \\
\text { (SE) }\end{array}$ & $\begin{array}{l}\text { Northern } \\
\text { Europe } \\
(\mathrm{NL}+\mathrm{SW})\end{array}$ & $P$ \\
\hline$A^{*}$ & 3.34 & 2.38 & $\mathbf{0 . 0 4 6 \dagger}$ \\
$H_{\mathrm{O}}$ & 0.11 & 0.03 & $\mathbf{0 . 0 0 2}$ \\
$H_{\mathrm{E}}$ & 0.55 & 0.41 & 0.070 \\
$F_{\mathrm{IS}}$ & 0.80 & 0.94 & $\mathbf{0 . 0 0 6}$ \\
$F_{\mathrm{ST}}$ & 0.34 & 0.49 & 0.135 \\
\hline
\end{tabular}

$A$, the mean number of alleles calculated after rarefaction method; $H_{\mathrm{O}}$, the observed heterozygosity; $H_{\mathrm{E}}$, the gene diversity; $F_{\mathrm{IS}}$ and $F_{\mathrm{ST}}$ values are estimated according to Weir \& Cockerham (1984). Probability values for differences between regions are given for two-sided tests, after 10000 permutations. Analyses performed with $F_{\text {STAT }}$ software.

*Allelic richness based on minimum sample size of 10 diploid individuals.

$+P$-value for one-sided tests is $0.029 ; P$ values in bold are significant.

were thus significantly higher in the north ( $s=0.94$ vs. 0.89 ; Mann-Whitney $U$-test $=54 ; P=0.034)$. Northern Europe also had significantly fewer alleles than southern Europe (Table 4). The latter result is consistent with the pattern expected under the postglacial colonization hypothesis where alleles are lost as a species migrates progressively northwards. It is important to note that populations surveyed from seeds (future genotypes) did not show systematically different levels of allelic richness than populations surveyed from leaves (existing genotypes) at either betweenor within-region scales. Populations from southern Europe and the Netherlands were surveyed from seeds and yet differed greatly in allelic richness (Tables 2 and 3) while within Sweden, allelic richness for populations 11 and 12 (analysed from seeds) did not differ from the other Swedish populations which were surveyed from leaves (Table 2).

\section{Among-population differentiation}

Owing to the high variability of microsatellite loci, estimates of differentiation may be low because maximum values for $F_{\mathrm{ST}}$ are less than one (i.e. maximum value $\left.=1-H_{\mathrm{S}}\right)($ Hedrick 1999). However, high levels of differentiation were always observed. The global $F_{\mathrm{ST}}$ was $0.46\left(\max F_{\mathrm{ST}}=0.56\right)$ and significantly greater than zero (exact test: $P<0.001$ ), and estimates per locus ranged from 0.35 (WMM20) to 0.57 (WMM22) (data not shown). The estimates of $F_{\mathrm{ST}}$ within the three geographical regions ranged from 0.34 (maximum $=0.45)(\mathrm{SE})$ to 0.60 (maximum $=0.66)(\mathrm{NL})$ but these values are not significantly different from one another (Table 3 ). Similarly, the estimates of $F_{\mathrm{ST}}$ within northern $(\mathrm{NL}+\mathrm{SW})$ and southern Europe did not differ significantly (Table 4). This suggests that local population dynamics (gene flow, 
A

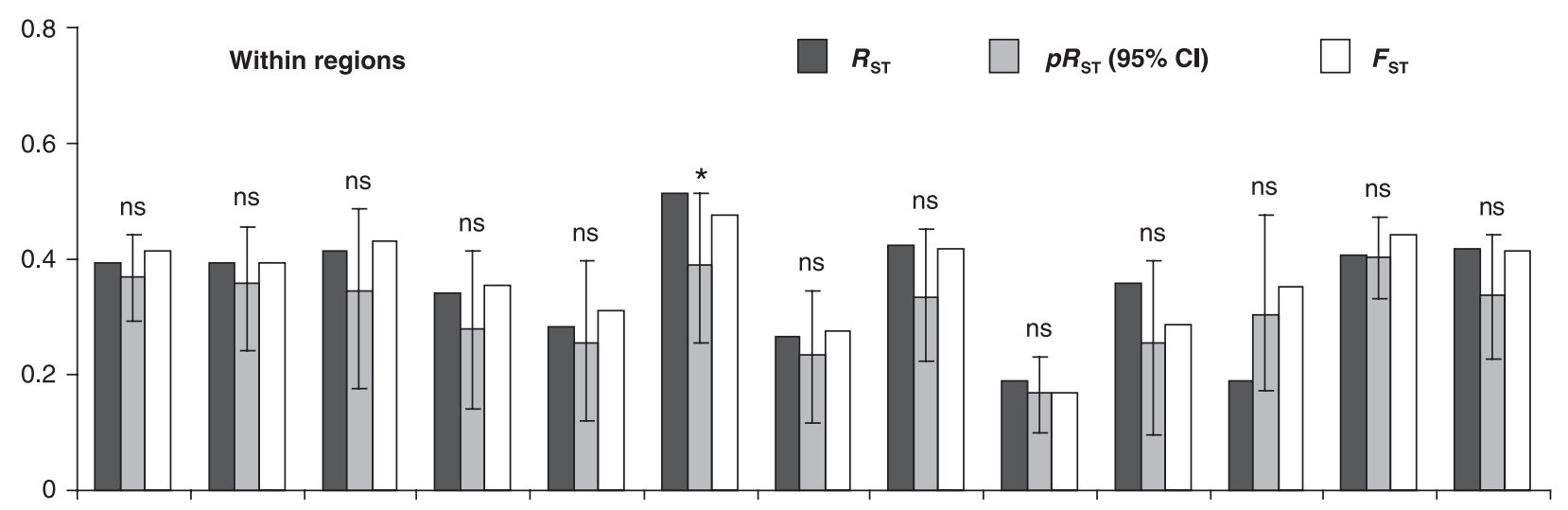

B

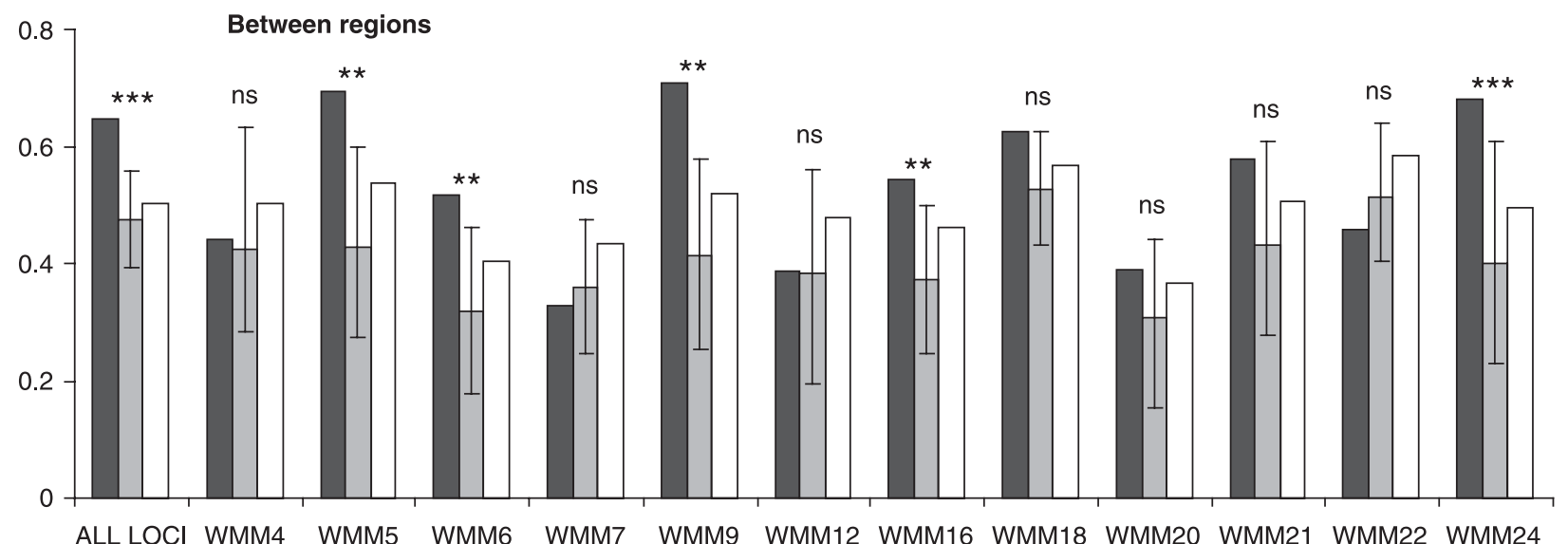

Fig. 3 Mean pairwise $R_{\mathrm{ST}}, p R_{\mathrm{ST}}, F_{\mathrm{ST}}$ values between European populations of Mycelis muralis for populations belonging to the same region (A) or different regions (B). Values are given for the multilocus estimates and each locus separately. The bars of $p R_{\mathrm{ST}}$ indicate the $95 \%$ confidence interval estimated over 1000 allele size permutations. Mean $R_{\mathrm{ST}}$ values that do not lie in the $p R_{\mathrm{ST}}$ intervals are considered as significantly different from $F_{\mathrm{ST}}$ values. $P$ values are denoted as follows: ns, nonsignificant, ${ }^{*} P<0.05,{ }^{* *} P<0.01$, and ${ }^{* * *} P<0.001$.

local colonization-extinction, selfing) primarily determine the distributions of variation among populations and may have masked the higher genetic differentiation expected in northern regions as a result of more recent founding following postglacial migration.

Average pairwise $R_{\mathrm{ST}}$ and $F_{\mathrm{ST}}$ values between pairs of populations within regions and between pairs of populations among regions are presented in Fig. 3(A,B), respectively. Mean pairwise multilocus estimates were $R_{\mathrm{ST}}=0.39, F_{\mathrm{ST}}=$ 0.41 within regions (Fig. $3 \mathrm{~A}$ ), and $R_{\mathrm{ST}}=0.65, F_{\mathrm{ST}}=0.50$ among regions (Fig. $3 \mathrm{~B}$ ), indicating that not only is differentiation among regions higher than within regions, the increase in differentiation from smaller to larger scales is stronger for $R_{\mathrm{ST}}(0.39-0.65)$ than for $F_{\mathrm{ST}}(0.41-0.50)$. Average pairwise $R_{\mathrm{ST}}$ and $F_{\mathrm{ST}}$ did not differ within regions, while $R_{\mathrm{ST}}$ was significantly larger than $F_{\mathrm{ST}}$ among regions. The observed $R_{\mathrm{ST}}$ values within regions are within the $95 \%$ confidence interval of $p R_{\mathrm{ST}}$ for the multilocus estimate, and for each of the loci except WMM9. In contrast, the observed $R_{\mathrm{ST}}$ values among regions are larger than the $95 \%$ range of $p R_{\mathrm{ST}}$ for the multilocus estimate, and for five of 12 loci. These results demonstrate that stepwise-like mutations contribute to population differentiation at the trans-European scale, but not at the regional scale. Note however, that the five loci contributing to these differences among regions (Fig. 3B) are those at which Sweden had private alleles (loci WMM5, WMM6, WMM9, WMM16 and WMM24, Appendix I).

A longer divergence time was also expected between more distant regions, and thus it was also expected that stepwiselike mutation should contribute more to differentiation between southern Europe and Sweden than between either southern Europe and the Netherlands, or the Netherlands and Sweden. This was examined by comparing $R_{\mathrm{ST}}$ and $p R_{\mathrm{ST}}$ among regions, performed for all pairs of regions separately. Multilocus estimates of $R_{\mathrm{ST}}$ were always larger than the $95 \%$ range of $p R_{\mathrm{ST}}(\mathrm{SE} / \mathrm{NL}, P=0.020 ; \mathrm{NL} / \mathrm{SW}$, $P=0.013 ;$ SE $/ \mathrm{SW}, P<0.001)$. However, the results obtained for these three analyses differed for single locus estimates. $R_{\mathrm{ST}}$ was larger than the $95 \%$ range of $p R_{\mathrm{ST}}$ for only one 
Table 5 Wright's F-statistics estimated for a two-level hierarchical design. Standard deviations estimated with jack-knife over loci are in parentheses

\begin{tabular}{llll}
\hline$F_{\text {IS }}$ & $F_{\text {IT }}$ & $F_{\text {SR }}$ & $F_{\text {RT }}$ \\
\hline $\begin{array}{l}0.931 \\
( \pm 0.007)\end{array}$ & $\begin{array}{l}0.866 \\
( \pm 0.011)\end{array}$ & $\begin{array}{l}0.482 \\
( \pm 0.020)\end{array}$ & $\begin{array}{l}0.122 \\
( \pm 0.032)\end{array}$ \\
\hline
\end{tabular}

All parameters estimated using TFPGA software.

locus for the pair SE/NL, but was larger for five and six loci for the pairs NL/SW and SE/SW, respectively. These results demonstrate that stepwise-like mutations contributed more (i.e. at more loci) to population differentiation between Sweden and the two other European regions, than between southern Europe and the Netherlands.

Hierarchical analysis of genetic variation showed significant differentiation both within and among regions (Table 5). Genetic differentiation among populations within regions $\left(F_{\mathrm{SR}}=0.482\right)$ was much higher than between regions $\left(F_{\mathrm{RT}}\right.$ $=0.122$ ). Analysis of molecular variance provided similar results (Table 6), showing that most of the variation was found within populations (50\%) or among populations within regions (39\%), while differences among regions only accounted for $11 \%$ of the total variation. When considering the three regions separately, a similar partitioning was obtained for southern Europe and Sweden, with 61\% and $57 \%$ of the variation found within populations, and $39 \%$ and $43 \%$ of the variation found among populations, respectively. Results for the Netherlands differed from this general pattern as most of the variation was found among populations $(72 \%)$ and not within $(28 \%)$, although population 8 may have exerted a disproportionately large influence on this result.

Correspondence analysis performed on allelic frequencies revealed the pattern of differentiation between populations (Fig. 4). The first three factorial axes explain 34.9\% of the total genetic variance. Eigenvalues of the factorial axes are $0.62,0.45$ and 0.42 , respectively, for the first,
A

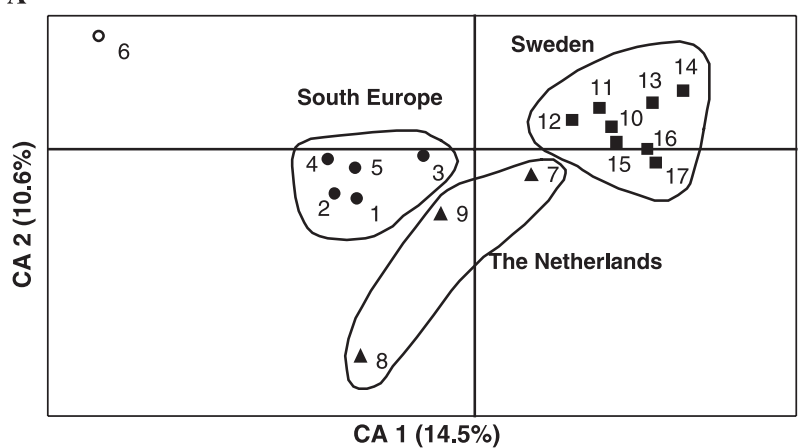

B

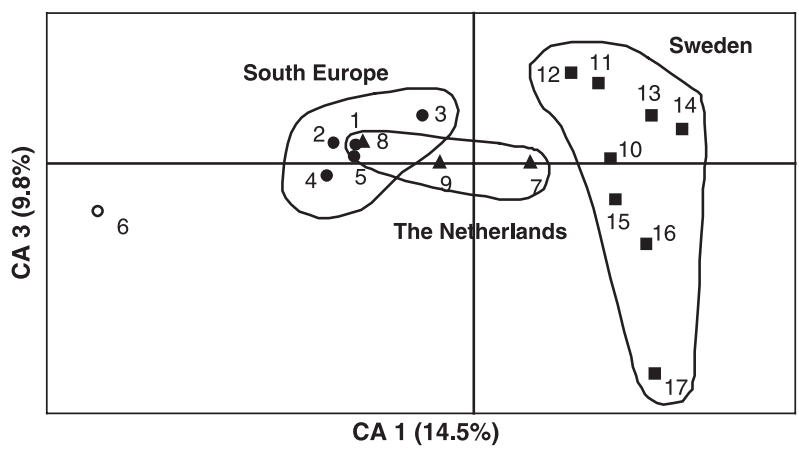

Fig. 4 Genetic differentiation among Mycelis muralis populations based on factorial correspondence analysis of allelic frequencies at 12 microsatellite loci. (A) Projection on the plane defined by the two first factorial axes. (B) Projection on the plane defined by the first and the third factorial axes. Populations are numbered according to the codes used in Table 1. The open symbol represents a population that does not group with others from the same geographical area.

second and third axes, confirming the existence of strong differentiation among samples. In both projection planes, populations from single regions clearly clustered together, illustrating the differentiation between regions observed in our other analyses. However, the diameters of each regional cluster are large, often larger than the distances between clusters, which illustrates that more variation is

Table 6 Analysis of molecular variance (AMOvA) conducted for 17 populations distributed in three regions: southern Europe $(N=6)$, The Netherlands $(N=3)$ and Sweden $(N=8)$

\begin{tabular}{lcccc}
\hline Source of variation & $\begin{array}{l}\text { Degrees } \\
\text { of freedom }\end{array}$ & $\begin{array}{l}\text { Sum of } \\
\text { squares }\end{array}$ & $\begin{array}{l}\text { Variance } \\
\text { components }\end{array}$ & $\begin{array}{l}\text { Percentage } \\
\text { of variation }\end{array}$ \\
\hline Among regions & 2 & 313.48 & 0.420 & 10.61 \\
Among populations within regions & 14 & 933.92 & 1.539 & 38.88 \\
Within populations & 701 & 1400.88 & 1.998 & 50.50 \\
Total & 717 & 2648.28 & 3.957 & \\
\hline
\end{tabular}

Fixation indices: $F_{\mathrm{ST}}=0.49, F_{\mathrm{SR}}=0.44, F_{\mathrm{RT}}=0.11$.

Analysis performed with ARLEQUIN software. 
present among populations within regions than between regions.

\section{Discussion}

Historical vs. contemporary forces structuring genetic diversity

The life history traits and population dynamics that characterize Mycelis muralis, i.e. self-fertilization (Mejias 1994), metapopulation dynamics and potential longdistance seed dispersal (Clabby \& Osborne 1999), may have facilitated its colonization northwards from refugia after the last glaciation. Selfing, metapopulation dynamics and postglacial colonization are all expected to decrease genetic diversity within and increase genetic differentiation among populations. However, while selfing and metapopulation dynamics are local forces that may affect all regions, the effects of postglacial colonization are only expected in populations established after the last glaciation.

Comparison of $M$. muralis populations from southern and northern Europe provides some insights about the effects of postglacial colonization. As expected under the postglaciation hypothesis (Hewitt 1996, 2000), populations from northern Europe had a lower average allelic richness than southern Europe (Table 4). Moreover, more private alleles were observed in southern European populations (51) than in the Netherlands (two) or Sweden (19). These results are consistent with observations reported for other perennial herbs (Asclepias exaltata, Broyles 1998; and Silene regia, Dolan 1994), and suggest that some alleles present in southern Europe may have been lost during colonization northwards because they may not have been present in the long-distance dispersers. However, the lower allelic richness in recently colonized regions was not reflected in Nei's gene diversity index, $H_{\mathrm{E}}$, illustrating the fact that bottlenecks lead to loss of rare alleles while gene diversity strongly depends on the distribution of more common alleles (Nei et al. 1975). Differences between these two estimators of genetic diversity have previously been demonstrated in European beech (Comps et al. 2001). The similar trends observed in this tree and in our perennial herb species suggest, as emphasized by Comps et al. (2001) and Widmer \& Lexer (2001), that demonstration of the effects of postglacial colonization on genetic diversity may strongly depend on the estimator used to assess genetic diversity.

Contrary to what was expected under the postglaciation hypothesis, genetic differentiation among populations was not higher in the recently colonized regions (Tables 3 and 4). Moreover, the levels of differentiation within the regions were not only similar, they were high. One interpretation of these results is that the effects of local population turnover and gene exchange among populations, which act in each of the regions, are strong enough to obscure this aspect of the expected postglacial pattern. Even under random mating, it has been shown that arrays of populations undergoing recurrent extinction and colonization can be more highly differentiated than subdivided populations at equilibrium between gene flow and genetic drift (Whitlock \& McCauley 1990; Giles \& Goudet 1997; Ingvarsson et al. 1997; Giles et al. 1998). However, where selfing occurs within populations, colonization and migration processes interact to cause strong increases in the differentiation among populations (Whitlock \& McCauley 1990; Ingvarsson 2002). First, the effects of repeated bottlenecks during colonization can be extreme in selfing species because, in principle, single seeds can establish new populations, strongly reducing the genetic variation within and increasing the variance among populations. Second, pollen gene flow is a decreasing function of the selfing rate. Thus, in highly selfing species such as $M$. muralis, pollen migration, often regarded to be the primary mechanism of gene flow over longer distances in plants (Levin 1987; Liepelt et al. 2002), occurs at rates that are too low to compensate for reductions in within-population diversity caused by repeated colonization (Ingvarsson 2002).

The increased genetic differentiation expected in metapopulations of selfers as discussed above is the consequence of strong reductions in within-population genetic diversity (Ingvarsson 2002; Charlesworth 2003). However, with 50\% of the total genetic variance distributed within populations and 11 out of 16 populations with $H_{\mathrm{E}}$ ranging between 0.40 and 0.68 (Tables 2 and 6), our M. muralis populations contain rather high levels of within-population diversity compared to other selfing species (see Hamrick \& Godt 1996). The actual influence of population turnover on the genetic variability within populations depends on the balance between migration and colonization processes. If turnover rates are not too high, and propagule dispersal between demes is effective, migration between extant populations can augment or prevent the loss of diversity within demes (Freeland et al. 2000; Ingvarsson 2002; Charlesworth 2003). Given the high estimated selfing rates obtained in this study (Table 2), seed rather than pollen migration must account for the observed levels of within-population diversity. Mycelis muralis seeds are equipped with a pappus that could facilitate long-distance dispersal. Moreover, a separate study of genetic structure in an $M$. muralis metapopulation in Sweden does provide evidence of migration between distantly separated populations (S. Chauvet, B. E. Giles and L. Ericson, in preparation). Using the spatial distributions of identical nine-locus genotypes as a base, 10 different genotypes were detected that were common to between two and six populations each. These haplotypes could not have been created by recombination among other haplotypes found in the resident populations (probability estimates based on allelic frequencies within 
populations: $P<10^{-4}$ ). These results suggest that gene exchange via seeds between $M$. muralis populations separated by up to $20 \mathrm{~km}$ may be sufficiently high to introduce and maintain gene diversity within populations but not to homogenize gene frequencies among populations $\left(F_{\mathrm{ST}}=0.35\right)$.

The data in this study revealed a further difference between populations sampled from the 'refugial' (SE) and postglacially recolonized (NL, SW) regions. Populations in northern Europe had significantly lower proportions of heterozygotes $\left(H_{\mathrm{O}}\right)$ and significantly higher values of $F_{\mathrm{IS}}$ and selfing rates than populations in southern Europe (Tables 2, 3 and 4). A similar pattern has been reported in hermaphroditic slugs of the genus Arion which show breeding system variation (Jordaens et al. 2000). While this trend is interesting, there are several possible explanations. (i) Interactions between pollinator guilds and $M$. muralis may differ across Europe. (ii) Observed selfing rates could result from interactions with the environments where the material was collected. (iii) Highly selfing individuals may have had a selective advantage for establishing new populations during northward recolonization because they could produce propagules in the absence of mating partners (Baker 1955, 1967). Theoretical investigation of mating system selection in colonizing species suggests that mating system evolution will be complex, depending upon interactions between mode of selfing, inbreeding depression, perenniality and seed dormancy with population size and metapopulation dynamics (Pannell \& Barrett 1998, 2001). Further conclusions are thus premature without further investigation into the nature of selfing in M. muralis.

\section{Mutation in historical and contemporary contexts}

With microsatellite data, genetic structure can be estimated either on the basis of allelic identity $\left(F_{\mathrm{ST}}\right)$ or on the differences in allele size $\left(R_{\mathrm{ST}}\right)$ (Balloux \& Lugon Moulin 2002). Owing to their different properties with respect to mutation (Slatkin 1995; Rousset 1996), testing whether stepwise-like mutation has contributed to population divergence may provide valuable insights into the main causes of differentiation (drift vs. mutation) and thus into phylogeographical patterns (Pons \& Petit 1996; Hardy et al. 2003). When only the allelic identity was considered, the average pairwise differentiation between $M$. muralis populations among regions $\left(F_{\mathrm{ST}}=0.50\right)$ was slightly larger than that within regions $\left(F_{\mathrm{ST}}=0.41\right)$ (Fig. 3). This slight difference is consistent with results from hierarchical analyses and analyses of molecular variance where much of the genetic variance was distributed between populations within regions (Tables 5 and 6 ). When allele size was considered, the average pairwise differentiation between populations among regions $\left(R_{\mathrm{ST}}=0.65\right)$ was much larger than that within regions $\left(R_{\mathrm{ST}}=0.39\right)$. The comparison of $F_{\mathrm{ST}}$ and $R_{\mathrm{ST}}$ estimates further revealed that they did not differ from each other within regions, while $R_{\mathrm{ST}}$ was larger than $F_{\mathrm{ST}}$ among regions (Fig. 3). This result suggests that stepwise-like mutations have contributed to differentiation among regions but not among populations within regions, and implies that gene flow is sufficient to counteract the effects of mutation within but not among regions. Two scenarios could account for this result. The rate of migrant exchange among regions could be lower than the mutation rate. Alternatively, populations from the different regions may have been separated for a sufficiently long time for mutations to accumulate (Hardy et al. 2003). The latter case might be observed if postglacial colonization northwards took place rapidly after the end of the last glaciation, although this seems unlikely because conditions suitable for the establishment of M. muralis in Sweden have only existed for 7000-8000 years (Wallin 1996; Kullman 1998). For such large mutational differences to have accrued in this interval, the initially high migration rates would have to have ceased after the regions were colonized because continued rapid migration would likely have homogenized allele frequencies to a greater degree. A special case of the separation time argument would, however, occur if the regions were founded by migrants originating from different refugia, or if at least one of the regions represented a mixture of refugial sources. In this situation, analyses based on allele size variation would 'see' mixtures as mutations. Total regional separation time is extended in the sense that it would include the time spent in each refugium and the time required for northward migration in addition to the time elapsed since the regions were founded.

\section{Sweden and the Netherlands: different postglacial histories?}

If Sweden and the Netherlands have been colonized by dispersers originating solely from refugia in southern Europe then, with the exception of new alleles created by mutations, the alleles present in these regions should be subsets of alleles present in southern Europe. This hypothesis cannot be rejected for the Netherlands because only seven of the $48(15 \%)$ Dutch alleles are absent from southern Europe. In contrast, 24 of the 74 alleles found in Sweden (32\%) were not observed in samples from southern Europe. Although these alleles may be present in southern Europe but not sampled, several results suggest that admixture of alleles from at least two genetically differentiated refugia is the most likely cause of the differences between Sweden and the other two regions. First, genetic diversity was slightly higher in Sweden than it was in the Netherlands, both when considering all Swedish populations sampled (e.g. $A=2.54$ vs. 1.96) or only Swedish populations located in a geographical area comparable in size to that sampled in the Netherlands (i.e. populations $10-14: A=2.70$ vs. 1.96 ) 
(Tables 2 and 3). Second, the five loci (WMM5, WMM6, WMM9, WMM16, and WMM24) that contribute to the higher $R_{\mathrm{ST}}$ among regions (Fig. 3B) are those with Swedish private alleles (Appendix I). A closer examination of Appendix I reveals that only a few of these private alleles (WMM5 : 190 and WMM24 : 157, 161, 163, 175) occur at low frequencies in single populations, as one might expect with mutation. The majority of private alleles occur at much higher frequencies and usually in several populations across the geographical range sampled in Sweden (Appendix I). The latter observation implies that these alleles have also had time to spread throughout the region by migration and strengthens the hypothesis that mutation does not account for all these alleles, and that Sweden was more likely colonized by dispersers originating from southern Europe and at least one other refugium. Unfortunately, our data do not allow us to identify which of the other potential refugia could have given rise to the private alleles now observed in Sweden. Candidate refugia often identified by molecular data as sources of species now occupying northeastern Europe are the Balkans, Russia and, to a lesser extent, Italy (Hewitt 1996, 1999, 2000; Taberlet et al. 1998; Tarasov et al. 2000; Tyler 2002; Petit et al. 2003). Species belonging to the temperate deciduous forests with which $M$. muralis is now associated are known to have had refugia in the Iberian peninsula, Italy and the Balkans (Huntley \& Birks 1983; Bennett et al. 1991), and in a small area restricted to the east coast of the Black Sea (Tarasov et al. 2000). Although the current distribution of M. muralis (Fig. 1) and the location of the Black Sea refugium do not speak loudly for an eastern origin, only additional sampling will allow identification of which refugia, along with southern Europe, contributed the migrants that colonized Sweden.

\section{Conclusions}

The distribution and structure of the genetic diversity in $M$. muralis has been shown to be the result of both historical and contemporary forces. Allelic richness has been negatively affected in northern populations by postglacial colonization, while connectivity and efficient gene flow through seed dispersal between populations (or demes) may have partly compensated for this loss of genetic diversity, maintaining relatively high levels of variation even in northern populations. At a within-region scale, differentiation among populations seems mostly determined by selfing and population turnover associated with metapopulation dynamics. However, differentiation among regions also involved contributions from mutation. This latter result suggests either low migration rates among regions with respect to mutation rates, and/or a long divergence time between regions. Our results give support to the latter hypothesis because, in contrast to the Netherlands which appear to have been colonized by dispersers originating solely from southern Europe, Sweden was likely colonized by dispersers coming from southern Europe and at least one other refugium.

\section{Acknowledgements}

This study has been carried out with financial support from the Netherlands' Ministry of Agriculture, Nature and Food Safety and from the Commission of the European Community, Energy, Environment and Sustainable Development (EESD) specific RTD programme EVK2-CT-1999-00037 'Dynamics of plant dispersal-related traits in fragmented European habitats: consequences for species survival and landscape management'. It does not necessarily reflect its views and in no way anticipates the Commission's future policy in this area. We would like to thank E. Bijlsma-Meeles, V. Pettersson and Ylva Schnürer for help with plant sampling, F. Palstra, J. Veldsink and A. Östensson for help with microsatellite analyses, A. Dalecky for discussions, and P. K. Ingvarsson for helpful comments on the manuscript.

\section{References}

Avise JC (1994) Molecular Markers, Natural History and Evolution. Chapman \& Hall, New York.

Baker HG (1955) Self-compatibility and establishment after 'longdistance' dispersal. Evolution, 9, 347-348.

Baker HG (1967) Support for Baker's law - as a rule. Evolution, 21, 853-856.

Balloux F, Lugon Moulin N (2002) The estimation of population differentiation with microsatellite markers. Molecular Ecology, 11, 155-165.

Belkhir K, Borsa P, Chikhi L, Raufaste N, Bonhomme F (2002) GENETIX 4.03, Logiciel Sous Windows ${ }^{\mathrm{TM}}$ Pour la Génétique Des Populations. Laboratoire Génome, Populations, Interactions. CNRS UMR 5000, Université de Montpellier II, Montpellier, France.

Bennett KD, Tzedakis PC, Willis KJ (1991) Quarternary refugia of north European trees. Journal of Biogeography, 18, 103-115.

Broyles SB (1998) Postglacial migration and the loss of allozyme variation in northern populations of Asclepias exaltata (Asclepiadaceae). American Journal of Botany, 85, 1091-1097.

Cain ML, Milligan BG, Strand AE (2000) Long-distance seed dispersal in plant populations. American Journal of Botany, 87, 12171227.

Charlesworth D (2003) Effects of inbreeding on the genetic diversity of populations. Philosophical Transactions of the Royal Society of London Series B-Biological Sciences, 358, 1051-1070.

Clabby G, Osborne BA (1999) Mycelis muralis (L.) Dumort. (Lactuca muralis (L.) Gaertner). Journal of Ecology, 87, 156-172.

Clark JS, Fastie C, Hurtt G et al. (1998) Reid's paradox of rapid plant migration - dispersal theory and interpretation of paleoecological records. Bioscience, 48, 13-24.

Comes HP, Abbott RJ (2000) Random amplified polymorphic DNA (RAPD) and quantitative trait analyses across a major phylogeographical break in the Mediterranean ragwort Senecio gallicus Vill. (Asteraceae). Molecular Ecology, 9, 61-76.

Comps B, Gomory D, Letouzey J, Thiebaut B, Petit RJ (2001) Diverging trends between heterozygosity and allelic richness during postglacial colonization in the European beech. Genetics, 157, 389-397. 
Dolan RW (1994) Patterns of isozyme variation in relation to population-size, isolation, and phytogeographic history in royal catchfly (Silene regia Caryophyllaceae). American Journal of Botany, 81, 965-972.

Ellenberg H (1988) Vegetation Ecology of Central Europe. Cambridge University Press, Cambridge, UK.

Ford BA, McQueen DAR, Starr JR, Naczi RFC (1998) The impact of species-specific traits and phylogenetic relatedness on allozyme diversity in Carex sect. Phyllostachys (Cyperaceae). Plant Systematics and Evolution, 212, 13-29.

Freeland JR, Noble LR, Okamura B (2000) Genetic consequences of the metapopulation biology of a facultatively sexual freshwater invertebrate. Journal of Evolutionary Biology, 13, 383-395.

Giles BE, Goudet J (1997) Genetic differentiation in Silene dioica metapopulations: estimation of spatiotemporal effects in a successional plant species. American Naturalist, 149, 507-526.

Giles BE, Lundqvist E, Goudet J (1998) Restricted gene flow and subpopulation differentiation in Silene dioica. Heredity, 80, 715723.

Goudet J (2001) FSTAT, a Program to Estimate and Test Gene Diversities and Fixation Indices, version 2.9.3. Available from $h t t p: / /$ www.unil.ch/izea/softwares/fstat.html. Updated from Goudet (1995).

Hamrick JL, Godt MJW (1996) Effects of life history traits on genetic diversity in plant species. Philosophical Transactions of the Royal Society of London Series B-Biological Sciences, 351, 12911298 .

Hardy OJ, Vekemans X (2002) SPAGeDi: a versatile computer program to analyse spatial genetic structure at the individual or population levels. Molecular Ecology Notes, 2, 618-620.

Hardy OJ, Charbonnel N, Fréville H, Heuertz M (2003) Microsatellite allele sizes: a simple test to assess their significance on genetic differentiation. Genetics, 163, 1467-1482.

Hedrick PW (1999) Perspective: highly variable loci and their interpretation in evolution and conservation. Evolution, 53, 313318.

Hewitt GM (1996) Some genetic consequences of ice ages, and their role in divergence and speciation. Biological Journal of the Linnean Society, 58, 247-276.

Hewitt GM (1999) Post-glacial re-colonisation of European biota. Biological Journal of the Linnean Society, 68, 87-112.

Hewitt GM (2000) The genetic legacy of the Quaternary ice ages. Nature, 405, 907-913.

Hultén E, Fries M (1986) Atlas of North European Vascular Plants, North of the Tropic of Cancer. Koeltz Scientific Books, Königstein.

Huntley B, Birks HJB (1983) An Atlas of Past and Present Pollen Maps for Europe, 0-13000 Years Ago. Cambridge University Press, Cambridge.

Ingvarsson PK (2002) A metapopulation perspective on genetic diversity and differentiation in partially self-fertilizing plants. Evolution, 56, 2368-2373.

Ingvarsson PK, Olsson K, Ericson L (1997) Extinction-recolonization dynamics in the mycophagous beetle Phalacrus substriatus. Evolution, 51, 187-195.

Jarne P (1995) Mating system, bottlenecks and genetic polymorphism in hermaphroditic animals. Genetical Research, 65, 193-207.

Jordaens K, Geenen S, Reise H et al. (2000) Is there a geographical pattern in the breeding system of a complex of hermaphroditic slugs (Mollusca: Gastropoda: Carinarion)? Heredity, 85, 571579 .
Kullman L (1998) Non-analogous tree flora in the Scandes Mountains, Sweden, during the early Holocene - macrofossil evidence of rapid geographic spread and response to paleoclimate. Boreas, 27, 153-161.

Leberg PL (2002) Estimating allelic richness: effects of sample size and bottlenecks. Molecular Ecology, 11, 2445-2449.

Levin DA (1987) Local differentiation and the breeding structure of plant populations. In: Plant Evolutionary Biology (eds Gottlieb LD, Jain SK), pp. 305-329. Chapman \& Hall, London.

Liepelt S, Bialozyt R, Ziegenhagen B (2002) Wind-dispersed pollen mediates postglacial gene flow among refugia. Proceedings of the National Academy of Sciences of the United States of America, 99, 14590-14594.

Mahy G, Ennos RA, Jacquemart AL (1999) Allozyme variation and genetic structure of Calluna vulgaris (heather) populations in Scotland: the effect of postglacial recolonization. Heredity, 82, 654-660.

Mejias JA (1994) Self-fertility and associated flower head traits in the Iberian taxa of Lactuca and related genera (Asteraceae: Lactuceae). Plant Systematics and Evolution, 191, 147-160.

Miller MP (1997) Tools for population genetic analysis (TFPGA 1.3): a windows program for the analysis of allozyme and molecular population genetic data. Computer software distributed by the author.

Nei M, Maruyama T, Chakraborty R (1975) The bottleneck effect and genetic variability in populations. Evolution, 29, 110.

Pannell JR, Barrett SCH (1998) Baker's law revisited: reproductive assurance in a metapopulation. Evolution, 52, 657-668.

Pannell JR, Barrett SCH (2001) Effects of population size and metapopulation dynamics on a mating-system polymorphism. Theoretical Population Biology, 59, 145-155.

Petit RJ, Pineau E, Demesure B et al. (1997) Chloroplast DNA footprints of postglacial recolonization by oaks. Proceedings of the National Academy of Sciences of the U S A, 94, 9996-10001.

Petit RJ, Aguinagalde I, de Beaulieu JL et al. (2003) Glacial refugia: hotspots but not melting pots of genetic diversity. Science, 300, 1563-1565.

Pollak E (1987) On the theory of partially inbreeding finite populations. I. Partial selfing. Genetics, 117, 353-360.

Pons O, Petit RJ (1996) Measuring and testing genetic differentiation with ordered versus unordered alleles. Genetics, 144, 1237-1245.

Premoli AC, Souto CP, Rovere AE, Allnut TR, Newton AC (2002) Patterns of isozyme variation as indicators of biogeographic history in Pilgerodendron uviferum (D. Don) Florin. Diversity and Distributions, 8, 57-66.

Raymond M, Rousset F (1995) GENEPOP Version 1.2.: population genetics software for exact tests and ecumenicism. Journal of Heredity, 86, 248-249.

Rendell S, Ennos RA (2002) Chloroplast DNA diversity in Calluna vulgaris (heather) populations in Europe. Molecular Ecology, 11, 69-78.

Rousset F (1996) Equilibrium values of measures of population subdivision for stepwise mutation processes. Genetics, 142, 13571362.

Schneider S, Roessli D, Excoffier L (2000) ARLEQUIN, Version 2.000: a Software for Population Genetic Data Analysis. Genetics and Biometry Laboratory. University of Geneva, Geneva, Switzerland.

Slatkin M (1995) A measure of population subdivision based on microsatellite allele frequencies. Genetics, 139, 457-462. 
Taberlet P, Fumagalli L, Wust-Saucy AG, Cosson JF (1998) Comparative phylogeography and postglacial colonization routes in Europe. Molecular Ecology, 7, 453-464.

Tarasov PE, Volkova VS, Webb T et al. (2000) Last glacial maximum biomes reconstructed from pollen and plant macrofossil data from northern Eurasia. Journal of Biogeography, 27, 609-620.

Tyler T (2002) Large-scale geographic patterns of genetic variation in Melica nutans, a widespread Eurasian woodland grass. Plant Systematics and Evolution, 236, 73-87.

van der Velde M, Bijlsma R (2003) Phylogeography of five Polytrichum species within Europe. Biological Journal of the Linnean Society, 78, 203-213.

Wade MJ, McCauley DE (1988) Extinction and recolonizationtheir effects on the genetic differentiation of local-populations. Evolution, 42, 995-1005.

Wallin J-E (1996) History of sedentary farming in Ångermanland, northern Sweden, during the iron age and medieval period based on pollen analytical investigations. Vegetation History and Archaeobotany, 5, 301-312.

Weir BS, Cockerham CC (1984) Estimating F-statistics for the analysis of population structure. Evolution, 38, 1358-1370.

Whitlock MC, McCauley DE (1990) Some population genetic consequences of colony formation and extinction - genetic correlations within founding groups. Evolution, 44, 17171724.

Widmer A, Lexer C (2001) Glacial refugia: sanctuaries for allelic richness, but not for gene diversity. Trends in Ecology and Evolution, 16, 267-269.
This study was part of an integrative project aimed at understanding the evolution of seed dispersal traits in a fragmented landscape. S. Chauvet is a postdoctoral researcher whose main research interests are seed dispersal processes and their consequences in structuring diversity. M. van der Velde is interested in the evolutionary biology of plant genetic and breeding systems. The general interest of E. Imbert is plant population biology, and in particular evolution of seed dispersal. M.-L. Guillemin is a specialist in molecular biology. M. Mayol is interested in the ecology and evolution of organisms in fragmented landscapes and the phylogeography and speciation of plants in Mediterranean islands. M. Riba's interests are focused on the evolutionary ecology and conservation of endangered species, with particular concern on the evolution of dispersal and local adaptations. M. Smulders and B. Vosman are interested in the management of genetic diversity in human-influenced and fragmented populations in relation to life history traits of species. Lars Ericson's interest is the interaction between host plants and their natural enemies and how these interactions vary in space and time. R. Bijlsma leads a programme on Conservation \& Population Genetics that focuses, in addition to population genetic topics, on the processes of genetic erosion, inbreeding depression and extinction of small populations. Barbara Giles works primarily with plants, focusing on evolution in structured populations and the way in which different population genetic processes affect the distribution of genetic variation within and among populations. 


\section{Appendix I}

Allelic frequencies at the microsatellite loci studied. Code numbers for the populations followed those given in Table 1 ; - allele absent in sample; na, locus not analyse

\begin{tabular}{|c|c|c|c|c|c|c|c|c|c|c|c|c|c|c|c|c|c|c|}
\hline & & \multicolumn{6}{|c|}{ South Europe } & \multicolumn{3}{|c|}{ The Netherlands } & \multicolumn{8}{|c|}{ Sweden } \\
\hline & & 1 & 2 & 3 & 4 & 5 & 6 & 7 & 8 & 9 & 10 & 11 & 12 & 13 & 14 & 15 & 16 & 17 \\
\hline \multirow[t]{9}{*}{ WMM4 } & 241 & 0.03 & - & - & - & 0.03 & - & 0.45 & - & - & 0.35 & 0.76 & 0.65 & 0.86 & 0.30 & - & - & - \\
\hline & 243 & - & 0.44 & 0.33 & 0.35 & 0.42 & 0.82 & - & - & 0.20 & 0.14 & - & 0.35 & - & - & - & - & - \\
\hline & 245 & - & 0.19 & - & - & 0.55 & - & 0.55 & - & 0.80 & 0.52 & 0.24 & - & 0.14 & 0.70 & 1.00 & 1.00 & 1.00 \\
\hline & 247 & 0.50 & 0.35 & 0.53 & 0.20 & - & - & - & - & - & - & - & - & - & - & - & - & - \\
\hline & 249 & 0.47 & 0.02 & - & - & - & - & - & - & - & - & - & - & - & - & - & - & - \\
\hline & 251 & - & - & 0.07 & - & - & 0.15 & - & 1.00 & - & - & - & - & - & - & - & - & - \\
\hline & 253 & - & - & - & 0.45 & - & - & - & - & - & - & - & - & - & - & - & - & - \\
\hline & 261 & - & - & - & - & - & 0.04 & - & - & - & - & - & - & - & - & - & - & - \\
\hline & 263 & - & - & 0.07 & - & - & - & - & - & - & - & - & - & - & - & - & - & - \\
\hline \multirow[t]{16}{*}{ WMM5 } & 150 & - & - & - & - & 0.03 & - & - & - & - & - & - & - & - & - & - & - & - \\
\hline & 162 & - & 0.02 & 0.43 & 0.20 & - & - & - & - & - & - & - & - & - & - & - & - & - \\
\hline & 164 & 0.03 & 0.23 & - & 0.20 & 0.12 & - & - & - & - & - & - & - & - & - & - & - & - \\
\hline & 166 & - & 0.42 & - & 0.50 & 0.10 & - & - & - & - & - & - & - & - & - & - & - & - \\
\hline & 168 & 0.97 & 0.04 & 0.03 & - & 0.72 & 0.85 & - & - & - & - & - & - & - & - & - & - & - \\
\hline & 170 & - & 0.13 & - & - & 0.03 & - & - & - & 0.05 & - & - & - & - & - & - & - & - \\
\hline & 174 & - & - & - & - & - & - & - & - & - & - & - & - & - & - & 0.22 & - & 0.04 \\
\hline & 176 & - & - & - & - & - & - & 0.30 & - & - & - & - & - & - & - & 0.19 & - & 0.96 \\
\hline & 178 & - & - & - & - & - & - & 0.03 & - & 0.75 & 0.03 & - & - & - & - & 0.44 & 0.64 & - \\
\hline & 180 & - & 0.17 & - & - & - & - & 0.68 & - & 0.20 & 0.10 & - & - & 0.14 & 0.34 & 0.03 & - & - \\
\hline & 182 & - & - & - & 0.10 & - & - & - & - & - & 0.50 & - & 0.65 & 0.76 & - & - & 0.36 & - \\
\hline & 184 & - & - & - & - & - & - & - & - & - & 0.37 & 0.26 & - & 0.10 & 0.04 & 0.11 & - & - \\
\hline & 186 & - & - & 0.53 & - & - & - & - & - & - & - & 0.74 & - & - & 0.62 & - & - & - \\
\hline & 188 & - & - & - & - & - & - & - & 1.00 & - & - & - & 0.30 & - & - & - & - & - \\
\hline & 190 & - & - & - & - & - & - & - & - & - & - & - & 0.05 & - & - & - & - & - \\
\hline & 192 & - & - & - & - & - & 0.15 & - & - & - & - & - & - & - & - & - & - & - \\
\hline \multirow[t]{25}{*}{ WMM6 } & 118 & 0.03 & 0.33 & - & - & 0.03 & 0.54 & - & - & - & - & - & - & - & - & - & - & - \\
\hline & 120 & - & 0.02 & - & - & - & - & - & - & - & - & - & - & - & - & - & - & - \\
\hline & 138 & - & - & 0.33 & - & 0.58 & - & - & - & - & - & - & - & - & - & - & - & - \\
\hline & 140 & - & - & 0.60 & - & - & - & - & - & - & - & - & - & - & - & - & - & - \\
\hline & 148 & - & - & - & - & 0.25 & - & - & - & - & - & - & - & - & - & - & 0.36 & - \\
\hline & 150 & - & 0.08 & - & 0.30 & - & - & - & - & - & - & - & - & - & - & - & - & - \\
\hline & 152 & - & - & - & - & 0.03 & - & - & - & - & - & - & - & - & - & - & - & - \\
\hline & 154 & - & - & - & - & - & - & - & 1.00 & - & - & - & - & - & - & - & - & - \\
\hline & 156 & - & - & - & - & - & 0.04 & - & - & - & 0.03 & 0.02 & - & - & - & - & - & - \\
\hline & 158 & - & 0.10 & - & - & - & - & - & - & 0.08 & - & - & - & - & - & - & - & - \\
\hline & 160 & - & 0.04 & - & - & - & - & 0.53 & - & 0.73 & - & 0.12 & - & - & - & 0.42 & - & - \\
\hline & 162 & - & - & - & - & - & - & 0.28 & - & - & - & 0.07 & - & - & - & 0.36 & - & 0.24 \\
\hline & 164 & - & - & - & - & 0.10 & - & 0.20 & - & - & 0.16 & - & - & - & - & - & - & 0.61 \\
\hline & 166 & - & - & - & - & - & - & - & - & - & 0.07 & - & - & - & 0.50 & - & - & 0.11 \\
\hline & 168 & - & - & - & - & - & 0.39 & - & - & 0.20 & 0.31 & - & - & 0.10 & - & 0.22 & - & 0.04 \\
\hline & 170 & - & 0.06 & 0.07 & - & - & 0.04 & - & - & - & 0.03 & - & - & 0.57 & - & - & - & - \\
\hline & 172 & 0.37 & - & - & - & - & - & - & - & - & 0.07 & - & - & - & - & - & - & - \\
\hline & 174 & - & 0.25 & - & - & - & - & - & - & - & - & - & 0.33 & - & - & - & - & - \\
\hline & 176 & 0.61 & 0.10 & - & - & - & - & - & - & - & - & - & 0.03 & - & - & - & - & - \\
\hline & 178 & - & - & - & - & - & - & - & - & - & 0.10 & 0.79 & - & - & - & - & - & - \\
\hline & 180 & - & - & - & 0.10 & - & - & - & - & - & 0.07 & - & - & 0.24 & 0.20 & - & 0.64 & - \\
\hline & 182 & - & - & - & 0.25 & - & - & - & - & - & 0.07 & - & 0.05 & 0.10 & 0.26 & - & - & - \\
\hline & 184 & - & - & - & - & - & - & - & - & - & 0.02 & - & 0.50 & - & 0.04 & - & - & - \\
\hline & 186 & - & - & - & - & - & - & - & - & - & 0.07 & - & 0.10 & - & - & - & - & - \\
\hline & 192 & - & - & - & 0.35 & - & - & - & - & - & - & - & - & - & - & - & - & - \\
\hline
\end{tabular}


1406 S. CHAUVET ET AL.

Appendix I Continued

\begin{tabular}{|c|c|c|c|c|c|c|c|c|c|c|c|c|c|c|c|c|c|c|}
\hline & & \multicolumn{6}{|c|}{ South Europe } & \multicolumn{3}{|c|}{ The Netherlands } & \multicolumn{8}{|c|}{ Sweden } \\
\hline & & 1 & 2 & 3 & 4 & 5 & 6 & 7 & 8 & 9 & 10 & 11 & 12 & 13 & 14 & 15 & 16 & 17 \\
\hline \multirow[t]{6}{*}{ WMM7 } & 149 & - & - & 0.06 & - & - & 0.54 & - & - & - & na & - & - & na & na & na & na & na \\
\hline & 159 & 0.03 & 0.08 & - & - & - & - & - & - & - & na & - & 0.25 & na & na & na & na & na \\
\hline & 161 & - & 0.56 & 0.44 & 0.40 & 0.20 & 0.32 & - & 1.00 & - & na & - & - & na & na & na & na & na \\
\hline & 163 & 0.50 & 0.21 & - & 0.40 & 0.70 & 0.04 & 0.40 & - & 0.05 & na & 1.00 & 0.10 & na & na & na & na & na \\
\hline & 165 & 0.47 & 0.02 & - & 0.20 & - & 0.11 & 0.60 & - & 0.75 & na & - & 0.05 & na & na & na & na & na \\
\hline & 167 & - & 0.13 & 0.50 & - & 0.10 & - & - & - & 0.20 & na & - & 0.60 & na & na & na & na & na \\
\hline \multirow[t]{16}{*}{ WMM9 } & 241 & - & - & - & - & - & - & - & - & - & - & - & - & - & - & 0.56 & 0.64 & - \\
\hline & 257 & - & - & 0.50 & - & - & - & - & - & - & - & - & - & - & - & - & - & - \\
\hline & 259 & - & - & - & - & - & - & - & - & - & - & 0.19 & - & - & 0.70 & - & - & - \\
\hline & 261 & - & - & - & - & - & - & - & 1.00 & - & 0.47 & - & - & 0.76 & - & 0.14 & - & 0.80 \\
\hline & 263 & - & - & - & - & - & - & - & - & - & 0.13 & - & - & 0.19 & - & - & 0.36 & - \\
\hline & 265 & - & - & 0.47 & - & 0.03 & - & - & - & - & 0.35 & 0.76 & - & - & - & 0.11 & - & - \\
\hline & 267 & - & - & - & - & 0.05 & - & - & - & - & 0.05 & 0.05 & 1.00 & 0.05 & 0.30 & 0.19 & - & 0.21 \\
\hline & 269 & - & 0.02 & - & - & 0.10 & - & - & - & 0.20 & - & - & - & - & - & - & - & - \\
\hline & 271 & - & - & - & - & 0.25 & - & 0.68 & - & 0.05 & - & - & - & - & - & - & - & - \\
\hline & 273 & - & 0.17 & - & - & 0.25 & 0.11 & 0.05 & - & - & - & - & - & - & - & - & - & - \\
\hline & 275 & - & 0.10 & - & - & 0.10 & 0.48 & - & - & - & - & - & - & - & - & - & - & - \\
\hline & 277 & - & 0.02 & - & 0.20 & 0.12 & 0.41 & 0.28 & - & - & - & - & - & - & - & - & - & - \\
\hline & 279 & - & 0.27 & 0.03 & 0.80 & 0.08 & - & - & - & - & - & - & - & - & - & - & - & - \\
\hline & 281 & - & 0.38 & - & - & - & - & - & - & - & - & - & - & - & - & - & - & - \\
\hline & 283 & 1.00 & - & - & - & 0.02 & - & - & - & 0.75 & - & - & - & - & - & - & - & - \\
\hline & 291 & - & 0.04 & - & - & - & - & - & - & - & - & - & - & - & - & - & - & - \\
\hline \multirow[t]{18}{*}{ WMM12 } & 170 & - & - & - & - & 0.10 & - & 0.68 & - & 0.80 & - & - & - & - & - & - & - & - \\
\hline & 172 & - & 0.13 & 0.50 & - & 0.33 & - & - & - & - & 0.57 & 0.76 & 0.65 & 0.86 & 0.30 & 0.94 & 0.64 & 0.30 \\
\hline & 174 & - & 0.10 & - & - & - & - & 0.33 & - & - & - & - & - & 0.05 & - & - & - & - \\
\hline & 176 & 0.47 & 0.27 & - & - & - & - & - & - & - & - & - & - & - & - & - & - & - \\
\hline & 178 & - & - & - & - & - & 0.11 & - & - & - & - & - & - & - & - & - & - & - \\
\hline & 184 & - & 0.06 & - & - & - & 0.07 & - & - & - & - & - & - & - & - & - & - & - \\
\hline & 188 & - & 0.13 & - & - & - & - & - & - & - & - & - & - & - & - & - & - & - \\
\hline & 196 & - & - & - & - & 0.20 & - & - & - & 0.20 & 0.37 & 0.24 & 0.35 & 0.10 & - & - & - & - \\
\hline & 198 & 0.53 & 0.19 & 0.38 & 0.20 & 0.30 & - & - & - & - & - & - & - & - & - & - & - & - \\
\hline & 200 & - & - & 0.09 & - & - & 0.72 & - & - & - & - & - & - & - & - & - & - & - \\
\hline & 204 & - & - & 0.03 & - & - & - & - & - & - & - & - & - & - & - & - & - & - \\
\hline & 208 & - & - & - & - & 0.07 & 0.04 & - & - & - & - & - & - & - & 0.40 & - & - & - \\
\hline & 210 & - & 0.02 & - & - & - & - & - & - & - & - & - & - & - & - & 0.06 & - & - \\
\hline & 212 & - & 0.04 & - & 0.80 & - & 0.04 & - & - & - & 0.07 & - & - & - & - & - & 0.36 & 0.70 \\
\hline & 214 & - & 0.02 & - & - & - & - & - & - & - & - & - & - & - & 0.30 & - & - & - \\
\hline & 218 & - & 0.02 & - & - & - & - & - & 1.00 & - & - & - & - & - & - & - & - & - \\
\hline & 220 & - & 0.02 & - & - & - & - & - & - & - & - & - & - & - & - & - & - & - \\
\hline & 222 & - & - & - & - & - & 0.02 & - & - & - & - & - & - & - & - & - & - & - \\
\hline \multirow[t]{11}{*}{ WMM16 } & 152 & - & - & - & - & - & 0.85 & - & - & - & - & - & - & - & - & - & - & - \\
\hline & 154 & - & 0.11 & - & - & 0.15 & 0.04 & - & - & - & - & - & - & - & - & - & - & - \\
\hline & 156 & - & 0.04 & - & 0.45 & 0.23 & - & - & - & - & - & - & - & - & - & - & - & - \\
\hline & 158 & - & 0.46 & - & 0.35 & 0.12 & - & - & - & 0.20 & - & - & - & - & - & 0.19 & - & 0.13 \\
\hline & 160 & 0.95 & 0.11 & 0.53 & - & 0.20 & 0.11 & - & - & - & - & - & - & - & - & - & 0.36 & 0.83 \\
\hline & 162 & 0.05 & - & - & - & - & - & 0.10 & - & - & 0.07 & - & - & - & 0.26 & 0.58 & - & 0.05 \\
\hline & 164 & - & 0.13 & - & 0.20 & 0.20 & - & 0.80 & - & 0.05 & 0.19 & 0.79 & - & 0.05 & 0.28 & 0.14 & - & - \\
\hline & 166 & - & 0.15 & 0.07 & - & 0.10 & - & 0.10 & 1.00 & 0.75 & 0.31 & - & - & - & 0.02 & - & 0.64 & - \\
\hline & 168 & - & - & 0.40 & - & - & - & - & - & - & 0.05 & 0.21 & 0.85 & 0.26 & - & - & - & - \\
\hline & 170 & - & - & - & - & - & - & - & - & - & 0.14 & - & 0.15 & 0.69 & 0.44 & 0.08 & - & - \\
\hline & 172 & - & - & - & - & - & - & - & - & - & 0.24 & - & - & - & - & - & - & - \\
\hline
\end{tabular}


Appendix I Continued

\begin{tabular}{|c|c|c|c|c|c|c|c|c|c|c|c|c|c|c|c|c|c|c|}
\hline & & \multicolumn{6}{|c|}{ South Europe } & \multicolumn{3}{|c|}{ The Netherlands } & \multicolumn{8}{|c|}{ Sweden } \\
\hline & & 1 & 2 & 3 & 4 & 5 & 6 & 7 & 8 & 9 & 10 & 11 & 12 & 13 & 14 & 15 & 16 & 17 \\
\hline \multirow[t]{3}{*}{ WMM18 } & 244 & - & 0.40 & 0.47 & - & 0.30 & - & 0.73 & 1.00 & 1.00 & na & - & - & na & na & na & na & na \\
\hline & 274 & 0.53 & 0.15 & - & 0.30 & 0.55 & 0.65 & - & - & - & na & - & - & na & na & na & na & na \\
\hline & 280 & 0.47 & 0.46 & 0.53 & 0.70 & 0.15 & 0.35 & 0.28 & - & - & na & 1.00 & 1.00 & na & na & na & na & na \\
\hline \multirow[t]{9}{*}{ WMM20 } & 294 & - & 0.20 & - & - & - & - & - & - & - & - & - & - & - & - & - & - & - \\
\hline & 302 & - & 0.04 & - & - & - & - & - & - & - & - & - & - & - & - & - & - & - \\
\hline & 304 & - & - & - & - & 0.03 & 0.35 & - & - & - & - & - & - & - & - & - & - & - \\
\hline & 306 & 0.45 & 0.28 & 0.47 & - & 0.33 & 0.06 & - & 1.00 & 0.20 & - & - & - & - & - & 0.12 & - & - \\
\hline & 308 & 0.55 & 0.13 & 0.10 & 0.40 & 0.33 & 0.04 & - & - & - & 0.19 & - & - & - & 0.28 & 0.24 & - & 0.35 \\
\hline & 310 & - & 0.30 & 0.43 & 0.35 & - & 0.06 & 0.85 & - & 0.08 & 0.42 & 0.24 & - & - & 0.72 & 0.65 & 0.64 & 0.65 \\
\hline & 312 & - & 0.04 & - & - & 0.13 & 0.50 & 0.15 & - & 0.73 & 0.35 & 0.76 & 0.95 & 0.78 & - & - & 0.36 & - \\
\hline & 314 & - & - & - & - & 0.17 & - & - & - & - & 0.04 & - & 0.05 & 0.23 & - & - & - & - \\
\hline & 316 & - & - & - & 0.25 & - & - & - & - & - & - & - & - & - & - & - & - & - \\
\hline \multirow[t]{8}{*}{ WMM21 } & 154 & - & - & - & 0.25 & - & - & - & - & - & na & - & - & na & na & na & na & na \\
\hline & 156 & - & 0.02 & 0.57 & - & 0.09 & 0.33 & - & - & - & na & - & - & na & na & na & na & na \\
\hline & 158 & 0.50 & 0.65 & - & - & 0.26 & - & - & - & 0.75 & na & - & - & na & na & na & na & na \\
\hline & 160 & - & 0.15 & 0.07 & 0.35 & 0.36 & 0.67 & - & - & - & na & - & - & na & na & na & na & na \\
\hline & 162 & - & 0.10 & 0.36 & 0.40 & 0.16 & - & - & - & - & na & - & 0.65 & na & na & na & na & na \\
\hline & 164 & 0.47 & 0.08 & - & - & 0.03 & - & 0.35 & 1.00 & - & na & - & 0.35 & na & na & na & na & na \\
\hline & 166 & - & - & - & - & 0.10 & - & 0.65 & - & 0.25 & na & 1.00 & - & na & na & na & na & na \\
\hline & 168 & 0.03 & - & - & - & - & - & - & - & - & na & - & - & na & na & na & na & na \\
\hline \multirow[t]{10}{*}{ WMM22 } & 187 & - & 0.29 & - & - & - & - & - & - & - & - & - & - & - & - & - & - & - \\
\hline & 189 & 0.53 & 0.71 & 1.00 & 0.30 & 0.68 & 0.11 & 1.00 & - & 0.25 & 0.63 & - & - & 0.10 & 0.30 & 0.69 & - & - \\
\hline & 201 & - & - & - & - & - & - & - & - & - & 0.13 & - & 0.05 & - & - & - & 0.64 & 1.00 \\
\hline & 203 & 0.47 & - & - & - & 0.03 & - & - & - & - & 0.23 & 1.00 & 0.95 & 0.91 & 0.70 & 0.31 & 0.36 & - \\
\hline & 205 & - & - & - & - & 0.12 & 0.04 & - & 1.00 & - & - & - & - & - & - & - & - & - \\
\hline & 207 & - & - & - & - & - & - & - & - & 0.75 & - & - & - & - & - & - & - & - \\
\hline & 209 & - & - & - & - & - & 0.37 & - & - & - & - & - & - & - & - & - & - & - \\
\hline & 211 & - & - & - & 0.70 & 0.02 & 0.46 & - & - & - & - & - & - & - & - & - & - & - \\
\hline & 212 & - & - & - & - & - & 0.02 & - & - & - & - & - & - & - & - & - & - & - \\
\hline & 213 & - & - & - & - & 0.15 & - & - & - & - & - & - & - & - & - & - & - & - \\
\hline \multirow[t]{12}{*}{ WMM24 } & 145 & 0.03 & - & - & - & - & 0.85 & - & - & 0.20 & - & - & - & - & - & - & - & - \\
\hline & 147 & 0.55 & 0.75 & - & 0.80 & 0.72 & 0.15 & - & 0.70 & 0.75 & - & - & - & - & - & - & - & - \\
\hline & 149 & - & 0.04 & - & 0.15 & 0.23 & - & - & - & - & - & - & - & - & - & - & - & - \\
\hline & 157 & - & - & - & - & - & - & - & - & - & - & - & - & - & - & - & - & 0.04 \\
\hline & 161 & - & - & - & - & - & - & - & - & - & - & - & - & 0.05 & - & - & - & - \\
\hline & 163 & - & - & - & - & - & - & - & - & - & 0.03 & - & - & - & - & - & - & - \\
\hline & 165 & - & - & - & - & - & - & - & - & - & - & - & - & - & - & - & - & 0.87 \\
\hline & 167 & - & 0.15 & 0.53 & 0.05 & 0.05 & - & - & - & - & 0.10 & - & - & - & - & 0.22 & - & - \\
\hline & 169 & - & 0.06 & - & - & - & - & 0.38 & 0.30 & 0.05 & 0.30 & - & - & - & - & - & 0.64 & - \\
\hline & 171 & 0.42 & - & 0.47 & - & - & - & 0.63 & - & - & 0.50 & 0.86 & 0.65 & 0.95 & - & 0.58 & - & 0.09 \\
\hline & 173 & - & - & - & - & - & - & - & - & - & 0.07 & 0.14 & 0.35 & - & 0.96 & 0.19 & 0.36 & - \\
\hline & 175 & - & - & - & - & - & - & - & - & - & - & - & - & - & 0.04 & - & - & - \\
\hline
\end{tabular}

